\title{
Predator and shelter-size effects on coral reef fish and spiny lobster prey
}

\author{
David B. Eggleston ${ }^{1,4, *}$, Romuald N. Lipcius ${ }^{2,4}$, Jill J. Grover ${ }^{3,4}$ \\ ${ }^{1}$ North Carolina State University, Department of Marine, Earth and Atmospheric Sciences, Raleigh, \\ North Carolina 27695-8202, USA* \\ ${ }^{2}$ The College of William and Mary, School of Marine Science, Virginia Institute of Marine Science, Gloucester Pt., \\ Virginia 23062, USA \\ ${ }^{3}$ Oregon State University, College of Oceanic and Atmospheric Sciences, Hatfield Marine Science Center, Newport, \\ Oregon 97365, USA \\ ${ }^{4}$ Caribbean Marine Research Center, Lee Stocking Island, Exuma Cays, Bahamas
}

\begin{abstract}
Population dynamics of coral reef fishes and spiny lobster appear to be determined by varable recruitment interacting with post-settlement processes, particularly predation. The risk of predation may be modified by the scaling between prey and shelter size, which enhances the protective capacity of a reef. We experimentally tested these predictions by manipulating densities of predatory Nassau grouper Epinephelus striatus on 8 artificial patch reefs of 2 sizes (small, large) in a large seagrass bed near Lee Stocking lsland, Bahamas. We intially censused patch reefs for 7 mo, after which we randomly selected equivalent numbers of small and large reefs to serve as permanent grouper removal versus control (non-removal) reefs. We continued to census patch reefs for 12 mo after predators were removed from certain reefs. The abundance of predatory Nassau grouper and the size of shelters from predation jointly explained the observed distribution and abundance patterns of spiny lobster and reef fish prey inhabiting artificial patch reef habitats. For example, the abundance of small lobsters was highest in small reefs where Nassau grouper were experimentally removed. When we assessed the effects of predator abundance on all reef fish prey (1 to $10 \mathrm{~cm} \mathrm{TL}$ ), we were unable to detect any significant effects on prey abundance or species diversity due to low statistical power. However, the total abundance and species richness of medium size reef fish (4 to $10 \mathrm{~cm}$ TL) was signuficantly higher in smcll shelters from which grouper were removed. In comparing species' relative abundances on reefs with low versus high numbers and Nassau grouper, the results indicated that grouper reduce prey abundances in a generalized, non-selective pattern, with no difference in the number of rare versus common prey species that were extirpated. Thus, juvenile Nassau grouper inhabiting certain patch reefs produce a general predatory impact, whereby predation reduces prey abundance and diversity in proportion to the initial relative abundance of prey. Our results support the preciction that at certain scales of space and time, post-settlement predation is a critical determinant of population abundance and species diversity of reef-fish and spiny lobster prey, and that the effect of predation is mediated by the protective capacity of a reef
\end{abstract}

KEY WORDS: Coral-reef fishes Predation - Recruitment Shelter scalıng S Spiny lobster

\section{INTRODUCTION}

The search for mechanisms underlying population dynamics and community structure has often emphasized 2 central questions: (1) To what extent do predators control the distribution and abundance of their prey? and (2) What limits or determines the diversity of

-E-mail: eggleston@ncsu.edu

- Address for correspondence ecological communities? Experimental manipulations of predator density in the field has been a powerful empirical technique for addressing these questions in certain terrestrial (Bock et al. 1992, Joern 1992, Belvosky \& Slade 1993), freshwater (see reviews by Zaret 1980, Sih et al. 1985, Forrester 1994) and marine systems, particularly rocky intertidal and soft-bottom marine habitats (see reviews by Connell 1975, Underwood \& Denley 1984, Wilson 1991). In marine systems, prey responses to predator removals or exclusions 
have demonstrated the full range of possible outcomes including: (1) increased local species abundance (e.g. Connell 1961, Menge 1976, Peterson 1982, Eggleston \& Armstrong 1995) and richness (e.g. Virnstein 1977); (2) decreased species abundance and diversity (e.g. Paine 1974); (3) little effect on species abundance and diversity (e.g. Dayton 1971, Thrush 1986, Underwood \& Fairweather 1989); and (4) complex direct and indirect interactions (e.g. Kneib 1988, Posey \& Hines 1991). Conversely, difficulty in manipulating predators has inhibited progress in understanding and detecting the role of predation in structuring complex, coral reef fish (Hixon \& Beets 1993) and tropical invertebrate communities (review by Jones 1991). The difficulty in manipulating predator densities has been ascribed to the wide-ranging nature of piscine predators, and the large spatial scale of continuous reef tracts (review by Hixon 1991, Hixon \& Beets 1993).

Most community-level studies of reef fish assemblages have addressed questions of whether or not reef fish assemblages are structured by competition or recruitment limitation, or to a lesser degree predation. Studies during the early 1970s, which tended to focus on competition, concluded that limited resources resulted in both resource partitioning and equilibrial abundances of coral reef fishes (e.g. Smith \& Tyler 1973, Roughgarden 1974). During the mid-1970s, Sale $(1974,1975)$ challenged this view and suggested that, despite competition for space, a stochastic 'lottery' of pelagic larvae settling onto unpredictably available space precluded resource partitioning and resulted in non-equilibrial population sizes. The prevailing paradigm during the 1980s was that reef fish assemblages were 'recruitment limited', such that a low supply of larvae leads to low settlement, and local populations never reach levels where competition for space or other density-dependent processes (e.g. mortality) occur (Williams 1980, Doherty 1981, 1991, Victor 1983, 1986). Recently, a more pluralistic view has emerged which proposes that a combination of factors determine population change. In this scenario, local population dynamics are a function of variable recruitment interacting with variable post-settlement processes, particularly post-settlement predation (Shulman \& Ogden 1987, Warner \& Hughes 1988, Hixon 1991, Jones 1991). Evidence from correlative (Hixon \& Beets 1993) and manipulative (Doherty \& Sale 1985, Caley 1993, Carr \& Hixon 1995) field studies suggests that post-settlement predation can limit the abundance and species richness of reef fishes.

Predation can also influence the distribution and abundance of benthic, decapod crustaceans (e.g. crabs, shrimps, stomatopods) in shallow-water tropical systems. Benthic crustaceans are one of the most important components of the diets of fish foraging off- reef (Heck \& Weinstein 1989, Parrish 1989 and references therein). The impact of fish predation on mobile crustaceans has been examined using artificial reefs and predator exclusion cages (Reaka 1985, Eggleston et al. 1998). Reaka (1985) used artificial reefs, in conjunction with fish exclusion cages and barriers to prey movement, to examine the effects of fish predation on stomatopods in St. Croix, U.S. Virgin Islands. She found that predation was important in shallow habitats only when barriers to stomatopod migration were present, with predation pressure increasing on deeper reefs (Reaka 1985). Our previous work identified a negative relationship between predatory Nassau grouper inhabiting artificial patch reefs, and the density of crab prey foraging nocturnally in adjacent seagrass beds (Eggleston et al. 1998). Moreover, there was a 43 -fold decrease in crab densities in sites with patch reefs (and associated predators) compared to control sites without patch reefs (Eggleston et al. 1998). Spiny lobsters juveniles are also a common crustacean inhabitant of patch reef systems, and their distribution and abundance may be determined, in part, by patch reefassociated predators.

There is a growing body of evidence that predation risk may be moderated by the availability and size of refuges (Shulman 1984, Hixon \& Beets 1989, 1993, Eggleston et al. 1990). Many reef fishes, as well as invertebrate reef inhabitants such as spiny lobster, prefer hole sizes near their body size (Shulman 1984 , Hixon \& Beets 1989, 1993, Eggleston \& Lipcius 1992), and experimental results indicate that Caribbean spiny lobster (Panulirus argus) survival is enhanced when residing in crevices scaled according to their body size (Eggleston et al. 1990). Obligate crevice-dwellers or crevice associates such as reef fishes and spiny lobster are likely faced for all or part of their life history with a decline in the number of crevices as they grow (Caddy 1986, Caddy \& Stamatopoulos 1990), possibly leading to a population bottleneck (Steger 1987, Wahle \& Steneck 1991). Many benthic organisms that are dependent upon habitat refugia may suffer from a demographic bottleneck whereby predation-induced mortality rates increase as shelter becomes limiting (e.g. Werner \& Gilliam 1984, Steger 1987, Wahle \& Steneck 1991 and references therein).

In this study, we assessed the joint effects of predation intensity and shelter size on reef fish species abundance and diversity, and juvenile Caribbean spiny lobster abundance, within an experimental framework. We focused on predation intensity by Nassau grouper Epinephelus striatus, which is a large (up to $90 \mathrm{~cm}$ total length, TL) and common predator inhabiting coral reef systems throughout the Bahamas and Caribbean (Randall 1965, Smith 1972, Colin 1992, Beets \& Hixon 1994). Serranids such as Nassau grouper are considered to be 


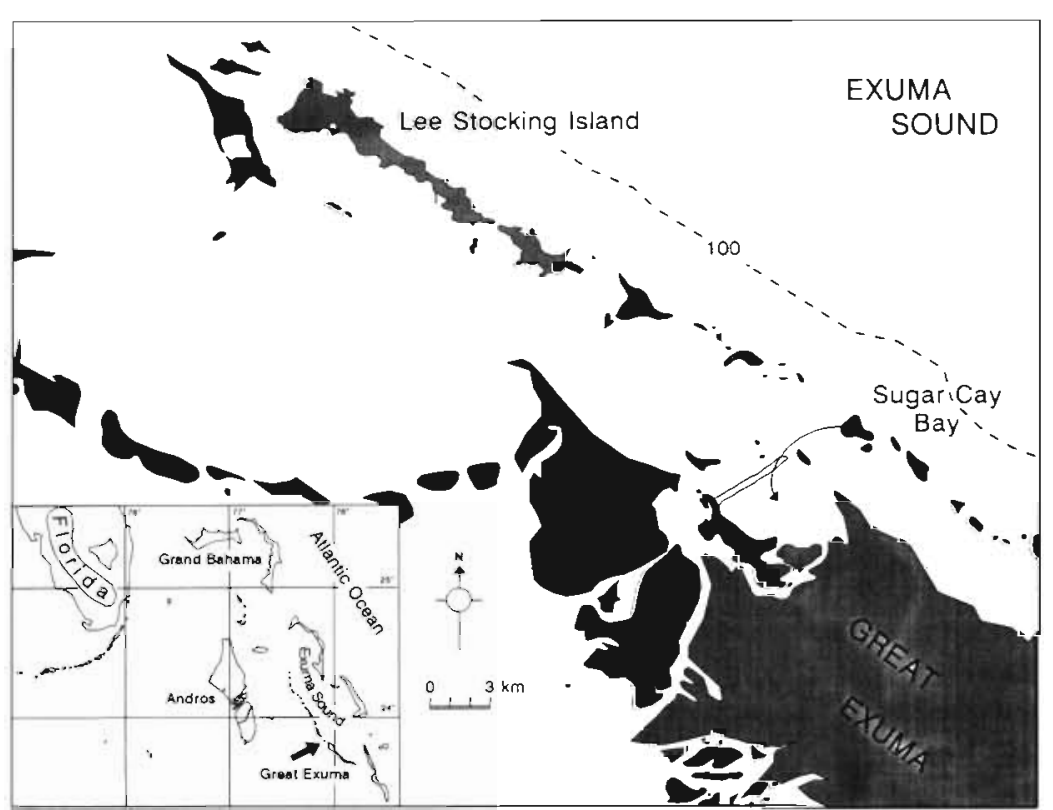

Fig. 1. Sugar Cay Bay study area near Lee Stocking Island, Bahamas $\left(23^{\circ} 45^{\prime} \mathrm{N}, 76^{\circ} 10^{\prime} \mathrm{W}\right)$ generally met these criteria.

Field observations and predator removals were conducted in Sugar Cay Bay (Fig. 1) near LSI. Sugar Cay Bay (Fig. 1) was chosen due to relatively high recruitment of Nassau grouper to artificial patch reefs at this site (Eggleston 1995). Sugar Cay Bay $\left(20 \mathrm{~km}^{2}\right)$ is composed of a shallow ( 2 to $3 \mathrm{~m}$ ), relatively homogeneous seagrass meadow (Thalassia testudinum) of moderate density $\left(\bar{x}=396\right.$ shoots $\mathrm{m}^{-2}, \mathrm{SD}=105$, $\mathrm{N}=12 \mathrm{~m}^{2}$ quadrats) that extended onto a very shallow $(0.5 \mathrm{~m})$ sand shoal to the north, with patch coral heads in the center (Fig. 1). Potential epi- and infaunal food resources, particularly gastropods (Cerithium spp.), were abundant. The dominant macroinvertebrates were conch (Strombus spp.) and nocturnally foraging crabs (Majidae, Portunidae, Calappidae, Xanthidae). Potential sour- among the most important predators in coral reef systems (Randall 1965, Shpigel \& Fishelson 1991, Kingsford 1992, Hixon \& Beets 1993, Beets \& Hixon 1994, Carr \& Hixon 1995, Eggleston et al. 1998), and exhibit high site fidelity (Beets \& Hixon 1994) making them amenable to experimental manipulation. We quantified community attributes (prey abundance, number of prey species) of reef-fish and spiny lobster prey associated with artificial patch reefs, with and without removal of predatory Nassau grouper.

\section{METHODS}

Field site and artificial patch reefs. Criteria for experimentally studying the effects of predation and prey refuges in structuring reef-fish and invertebrate assemblages (Caddy \& Campbell 1986, Hixon \& Beets 1993) include: (1) a relatively uniform study area with few natural shelters but an existing food supply; (2) model reefs located far enough from each other and natural patch reefs that they inhibit movement of animals between reefs and thereby serve as independent replicates; and (3) experimental areas closed to commercial and recreational fishing. Locations near Lee Stocking Island (LSI; Fig. 1), Exuma Cays, Bahamas ces of recruits colonizing artificial patch reefs were: (1) plankton for settling larvae; (2) the surrounding seagrass bed, as well as extensive macroalgal beds (primarily Laurencia spp.) located in mangrove creeks west of Sugar Cay Bay (Fig. 1), for small juveniles; and (3) local patch reefs for large juveniles and adults.

Our design of artificial patch reefs was based on 'casitas' (Fig. 2), which mimic rock and reef crevices. Casitas were constructed with a reinforced concrete roof bolted to a supporting PVC plastic pipe frame (Eggleston et al. 1990). Two casita sizes were used: small $(157.3 \times 105.1 \times 3.8 \mathrm{~cm}$ height of opening $)$ and large $(177 \times 118 \times 6 \mathrm{~cm})$. Reductions in casita opening height allowed entry of small fish and invertebrates

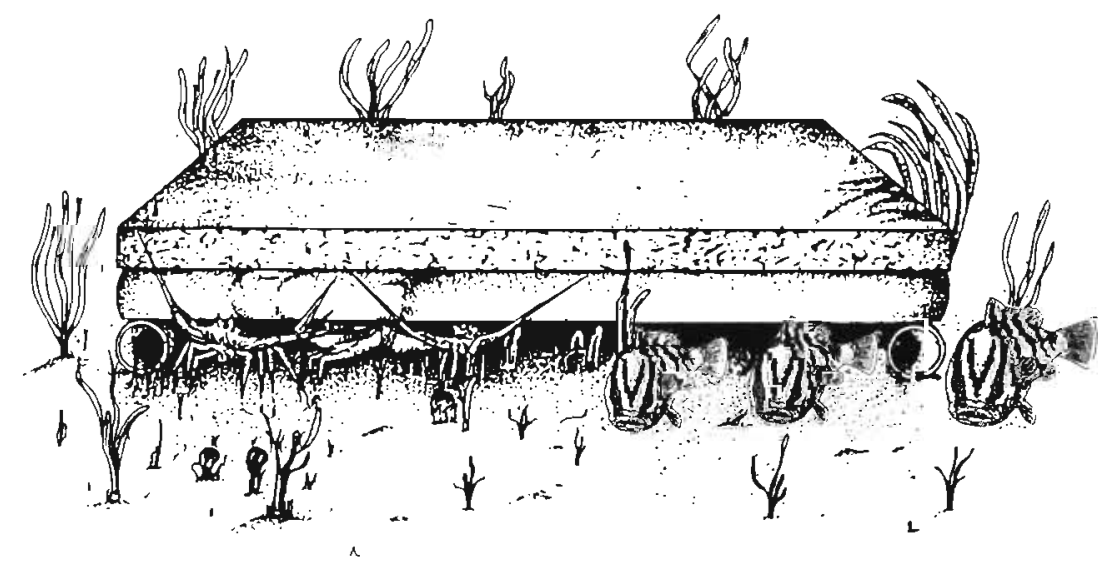

Fig. 2. A large casita (artificial patch reef) constructed with a frame of PVC pipe and with a cement roof $(177 \mathrm{~cm}$ length $\times 118 \mathrm{~cm}$ width $\times 6 \mathrm{~cm}$ height of opening) 
(i.e. $<3.8 \mathrm{~cm}$ body height) and excluded larger predators, particularly subadult Nassau grouper. The $3.8 \mathrm{~cm}$ opening height for small casitas did not set a strict upper limit to allowable body sizes since fish would sometimes enter on their sides and reside beneath the roof, which was 6 and $12 \mathrm{~cm}$ above the seafloor in small and large casitas, respectively. The small casita size was based on a 2-dimensional scaling equation, $R=$ $1 /(N)^{1 / 2}$ (Peitgen \& Saupe 1988), which accounted for the decreased opening height of the small casita, yet insured that the roof was identically scaled between small and large casitas (see Eggleston et al. 1990 for more details on the scaling procedure). In this equation, $N$ is the ratio of the large casita height $(6 \mathrm{~cm})$ to the small casita height $(3.8 \mathrm{~cm})$, and $R$ is the resultant scaling factor. Within Sugar Cay Bay, an equivalent number of large and small casitas were systematically interspersed and positioned approximately $35 \mathrm{~m}$ apart.

Visual censusing techniques and sampling períod. Casitas were censused visually each month by SCUBA from initial placement in January 1991 through termination of the experiment 19 mo later in July 1992. Casitas were censused during the first quarter of the new moon, the expected time of recruitment for most reef fishes (Victor 1986, Robertson 1992). During our casita censuses, species abundances and sizes of individuals were estimated. Planktivores and other active species hovering above a casita were quantified at a distance of approximately $3 \mathrm{~m}$ away; small juvenile species residing adjacent to the sides or just beneath the roof of a casita were then quantified as a diver slowly swam in a circle above the perimeter of the casita roof. Finally, demersal fish and macroinvertebrates residing beneath the casita roof or within the PVC-pipe frame were quantified. Fish total length (TL) and spiny lobster carapace length (CL) were estimated using a ruler attached perpendicular to the far end of a $70 \mathrm{~cm}$ rod held out from a diver (e.g. Bohnsack \& Bannerot 1986). This device increased the accuracy of visual estimations of body size. Fish sizes below and above $30 \mathrm{~cm}$ were estimated to the nearest $1 \mathrm{~cm}$ and $5 \mathrm{~cm}$, respectively, and lobster CL was estimated to the nearest $1 \mathrm{~cm}$. Species abundances above 20 per casita (common with Haemulidae spp. recruits) were grouped to the nearest 5 or 10 individuals.

Predator manipulation. During August 1991, 8 mo after initial casita deployment, we randomly selected equivalent numbers of small and large casitas to serve as permanent grouper removal versus control (nonremoval) reefs. Grouper were then removed from selected casitas within $2 \mathrm{~h}$ of dawn by spearfishing. Spearfishing was used because we were interested in examining stomach contents of grouper (Eggleston et al. 1998). Because grouper slowly recolonized casitas several months after removal, this procedure was re- peated after casita surveys in September and December 1991, and March and April 1992. Thus, grouper were removed from patch reefs a total of 5 times during a 12 mo period.

We used a 3-way fixed-factor ANOVA model with Date laveraged over 7 mo before grouper were removed, averaged over 12 mo after grouper were removed), Casita Size (small, large), and grouper Removal (removed, not-removed) as factors, and the mean number of grouper $(>15 \mathrm{~cm})$ per casita per census as the response variable. We chose a minimum size of $15 \mathrm{~cm}$ to define Nassau grouper as 'predators' based on stomach contents (Randall 1965) and previous observations (Clavijo et al. 1980. Hixon \& Beets 1993) of the minimum size at which this species becomes piscivorous. Grouper abundance at both sites was logtransformed $(x+1)$ to meet assumptions of normality and homogeneity of variance.

Tagging study. For individual casitas to serve as independent replicates, it was critical that the $35 \mathrm{~m}$ distance between casitas serve as an adequate barrier to appreciable movements of individuals between reefs. Small reef fish are often sedentary after settlement (Forrester 1990, Doherty 1991), and tagging studies with large piscivores (including Nassau grouper) have shown that residents exhibit considerable site fidelity to home reefs (Hixon \& Beets 1993, Beets \& Hixon 1994). Moreover, previous observations of predator movements (primarily lutjanids) and predation rates on tethered spiny lobster along a distance gradient from casitas indicated that $30 \mathrm{~m}$ was beyond the daytime foraging range of most casita-associated predators (Eggleston et al. 1992). Although these previous studies indicated strong site fidelity by small reef fishes and a foraging radius of $<30 \mathrm{~m}$ for casita-associated fishes, we were concerned about the potential predatory impact of grouper residing in control reefs to fish and spiny lobster prey residing in reefs where grouper were removed.

To test our assumption of statistical independence of Nassau grouper on individual casitas, we initiated a tagrecapture study on control reefs during February 1992. Grouper were captured by surrounding a casita with a circular net ( $4 \mathrm{~m}$ diameter $\times 1 \mathrm{~m}$ height $\times 2.5 \mathrm{~cm}$ mesh) and prodding fish into the conical end of the net with PVC pipes. Fish were then tagged with anchor tags inserted at the base of the dorsal fin, and returned to their capture casitas. A total of 34 grouper were tagged and released. The location of tagged grouper was recorded during subsequent monthly casita censuses.

Interactions between shelter and predation. To determine the interactive effects of grouper removal and shelter size on prey fish assemblages and abundance of juvenile spiny lobster, we employed a series of 3-way ANOVA models with Date laveraged over 7 mo 
before grouper removal, and averaged over $12 \mathrm{mo}$ after grouper removal), Casita Size (small, large), and grouper Removal (removed, not removed) as factors, and 7 individual response variables: (1) number of small lobsters ( 35 to $48 \mathrm{~mm}$ CL) per casita; (2) number of resident prey fish (1 to $10 \mathrm{~cm}$ ) per casita; (3) prey fish species richness (S) per casita; (4) prey fish evenness ( $E$ ) per casita; (5) number of resident medium size prey fish (4 to $10 \mathrm{~cm} \mathrm{TL}$ ) per casita; (6) medium prey fish $S$ per casita; and (7) medium prey fish $E$ per casita. Means were contrasted with Ryan's $Q$ multiple comparison test, as recommended by Day \& Quinn (1989). We assessed the response of small, juvenile lobsters ( 35 to $48 \mathrm{~mm}$ CL) to shelter size and grouper removal since previous tethering experiments at the 8 -casita site indicated that small lobsters suffered $80 \%$ predation-induced mortality. compared to only $5 \%$ for lobsters $>55 \mathrm{~mm}$ CL (D. Eggleston unpubl. data). Moreover, survival of small lobsters is presumably enhanced when they reside beneath small casitas compared to large ones (Eggleston et al. 1990, 1992). We hypothesized that small lobsters were preferentially residing with large conspecifics in large casitas, rather than in small casitas better scaled to their body size. Hence, we subsequently assessed the relationship between small and large lobster abundance both before and after grouper Removal with linear least-squares regression analysis.

We chose a 'prey' fish size range of 1 to $10 \mathrm{~cm}$ based on previous stomach content analysis (Randall 1965, Clavijo et al. 1980) and field observations (Hixon \& Beets 1993) which indicated that $15 \mathrm{~cm}$ Nassau grouper could readily consume fish as large as $10 \mathrm{~cm}$. We also examined the response of medium-sized prey (4 to $10 \mathrm{~cm} \mathrm{TL}$ ) to eliminate sporadically high numbers of 1 to $3 \mathrm{~cm}$ recruits (primarily Haemulidae spp.), which may have diminished shelter size and predator removal effects (i.e. predator swamping; e.g. Hixon \& Beets 1993). Species diversity consists of 2 components (Magurran 1988): species number (richness) and species abundances, which are both used to calculate equitability of relative abundances among species (evenness). To elucidate the mechanism(s) underlying predator affects on prey diversity, $S$ and $E$ were considered separately since they can vary independently (Magurran 1988). Evenness was calculated as the ratio of observed prey $S$ per casita to maximum prey $S$ (Pielou's 'J', Pielou 1966), as recommended by Magurran (1988). Finally, we examined the relationship between the abundance of grouper predators and each of the 7 prey response variables described above for the period after grouper were removed (August 1991 to July 1992), with linear least-squares regression techniques. When necessary, abundance, $S$, and $E$ data were log-transformed $(x+1)$ to meet assumptions of normality and homogeneity of variance.

\section{RESULTS}

\section{Predator manipulation}

Mean grouper abundance per casita varied according to Date, Casita Size and Removal (Table 1; Fig. 3A, $B$ ) however, significant Date $\times$ Casita Size and Date $\times$ Removal interaction effects precluded contrasts across the main effects (Table 1). The Date $\times$ Casita Size effect was due to significantly higher numbers of grouper residing in large versus small casitas during the 7 mo period before grouper were removed, compared to no difference in abundance between casita sizes during the 12 mo period after grouper were removed (Ryan's $Q$ test, Fig. 4A). The Date $\times$ Removal interaction effect was due to no significant difference in the mean number of grouper per casita between grouper Removal and Control (not-removed) casitas during the 7 mo period prior to grouper removal, but significantly higher numbers of grouper in Control versus Removal casitas during the 12 mo period after grouper were removed (Ryan's $Q$ test, Fig 4B). The outcome of the Date $\times$ Removal interaction was particularly noteworthy in that it verified that the grouper manipulation was successful.

Table 1. Three-way ANOVA table (model I). Effects of sampling Date (averaged over 7 mo before grouper were removed, averaged over 12 mo after grouper were removed), Casita Size (small, large), and grouper Removal (removed, not removed) upon the mean numbers of Nassau grouper predators per casita. Grouper abundance was log-transformed (+1) to standardize variances

\begin{tabular}{|lrcc|}
\hline Source of variation & df & MS & $F$ \\
\hline Date & 1 & 0.74 & $10.96^{\circ}$ \\
Casita Size & 1 & 4.00 & $59.20^{\circ}$ \\
Removal & 1 & 4.26 & $63.06^{\circ}$ \\
Date $\times$ Casita Size & 1 & 0.79 & $11.65^{\circ}$ \\
Date $\times$ Removal & 1 & 1.19 & $17.61^{\circ}$ \\
Casita Size $\times$ Removal & 1 & 0.01 & $0.01 \mathrm{NS}$ \\
Date $\times$ Casita Size $\times$ Removal & 1 & 0.01 & $0.17 \mathrm{NS}$ \\
Error & 144 & 0.07 & \\
NS: $p>0.05 ; " p<0.001$ & & & \\
\hline
\end{tabular}

\section{Tagging study}

None of the 34 Nassau grouper tagged from Control casitas during February 1992 was ever observed in casitas other than where each was tagged. The tags persisted in these fish for up to $4 \mathrm{mo}$, but became hard to read after 2 mo. Accelerated tag loss 

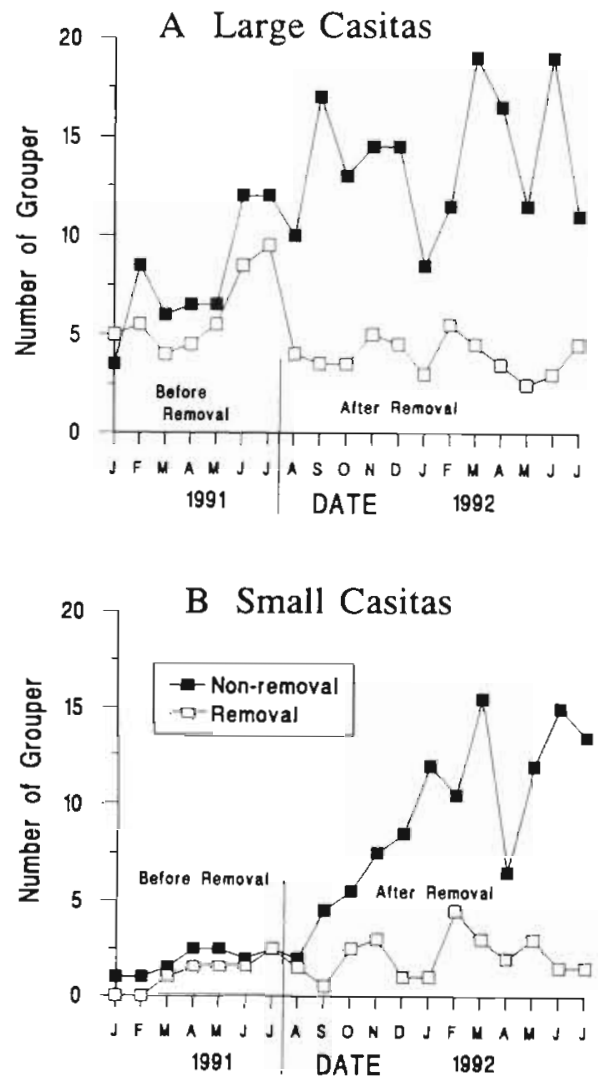

Fig. 3. Effects of sampling Date $(7$ mo before grouper were removed, 12 mo after grouper were removed), and grouper Removal (not removed, removed) on the mean number of Nassau grouper predators per casita per census residing in (A) large and (B) small casitas. Grouper abundances were back-transformed. $N=2$. Error bars were eliminated for clarity; see Table 1 tor significance levels

appeared to be due to abrasion of the tags by the concrete roof of the casitas as grouper moved around within a casita. During 1992 we observed 24 marked fish in March, 17 in April, 8 in May, and none in June. During these monthly observations it was apparent that the length of the tags was being reduced due to abrasion. Nevertheless, grouper in this study displayed high fidelity to a particular casita such that individual casitas served as statistically independent replicates.

\section{General patterns of casita faunal abundance}

During the 19 mo study period, we recorded a total of 53 fish species from 25 families on or near casitas (Appendix A). During each monthly census, we observed an average of 22 to 36 fish and 17 to 29 fish species per casita, depending upon the treatment (Appendix 1). We also recorded an average of 0 to 12
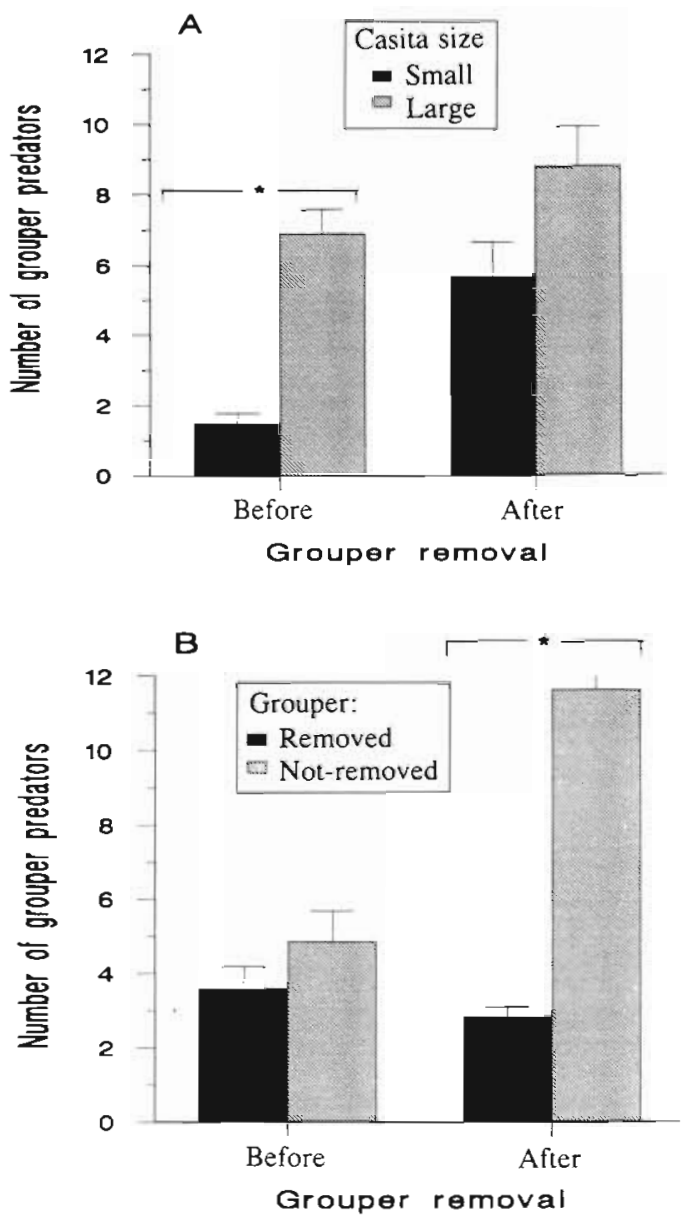

Fig. 4. Effects of sampling Date (averaged over 7 mo before grouper were removed, averaged over 12 mo after grouper were removed) on the number of Nassau grouper predators residing in (A) small versus large casitas, and (B) grouper Removal versus Control (Not-removed) casitas at the 8-casita site. $N=2$. Values are back-transformed means per casita $+1 \mathrm{SE}$ * Treatments that are significantly different at the 0.05 level

small spiny lobster per casita per month, depending on the treatment (Fig. 5). Nassau grouper was the predominant, large resident predator on casitas, whereas grunt recruits and small spiny lobster were the predominant potential prey (reef fish: Appendix 1; spiny lobster: Fig. 5). Other resident, large predators included snapper, trumpetfish and spotted moray eels (Appendix 1), and an occasional Octopus spp. All resident fish $<10 \mathrm{~cm}$ were considered to be potential prey for these predators. We excluded from analyses 11 species that visited the reefs sporadically as being obvious transients. We included wrasses such as slippery dicks and clown wrasse in the transient category as these species are general inhabitants of seagrass beds and would often follow divers from one casita census to another. Transient predators included snap- 

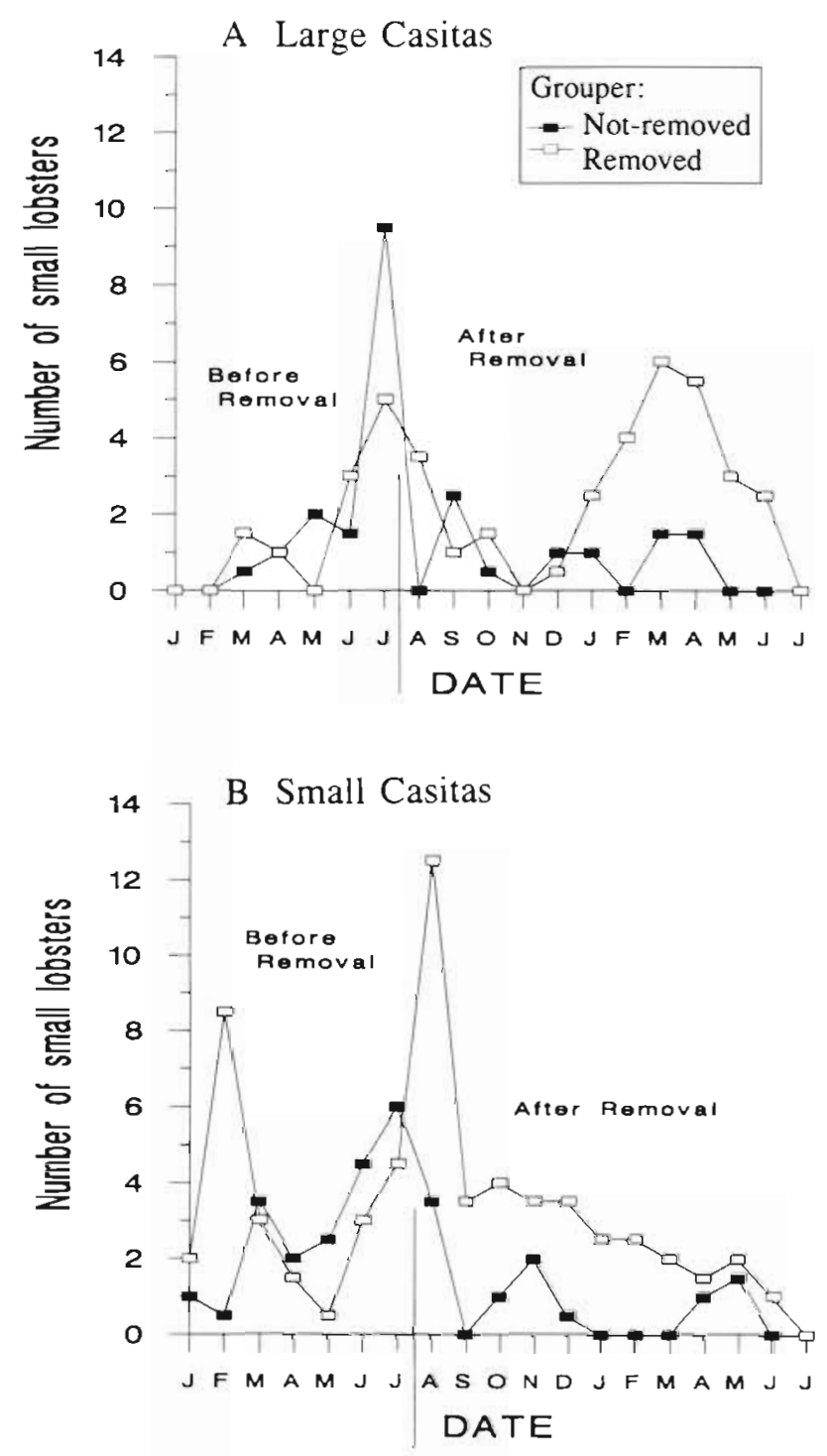

Fig. 5. Effects of samplung Date 7 mo before grouper were removed, 12 mo after grouper were removed), and grouper Removal (not removed, removed) on the mean number of small spiny lobsters ( 35 to $48 \mathrm{~mm}$ CL) per casita per census residing in (A) large and (B) small casitas at the 8-casita site. $N=2$. Error bars were eliminated for clarity; see Table 2 for significance levels

per, jacks, barracuda and jolthead porgy. Our criterion for distinguishing predator ( $>15 \mathrm{~cm}$ TL) and prey $(<10 \mathrm{~cm} \mathrm{TL})$ resulted in losing $14 \%$ of the total number of reef fish censused between 10 and $15 \mathrm{~cm}$ TL from data analyses. The species observed residing on or near casitas were typical of the most common species inhabiting natural patch reefs in Caribbean areas (Randall 1965, Clavijo et al. 1980, Hixon \& Beets 1993), and represented all major foraging guilds (Appendix 1). These patterns suggest that reef fish assemblages associated with casitas were ecologically realistic and representative.

\section{Interactive effects of shelter size and predators}

$$
\text { Small spiny lobster prey }
$$

Mean lobster abundance per casita varied as a function of Casita Size and grouper Removal (Table 2); however, significant Date $\times$ Casita Size and Casita Size $\times$ grouper Removal interactions precluded contrasts across the main effects (Table 2). The Date $\times$ Casita Size interaction was due to significantly higher numbers of small juvenile lobsters in large versus small casitas before grouper removal, and no difference in mean abundance between casita sizes after grouper removal (Ryan's $Q$ test; Fig. 6A). Before grouper removal, there was a weakly positive but significant relationship between small and large lobster abundance $\left(F=6.89, \mathrm{df}=1,54, \mathrm{p}=0.01, \mathrm{R}^{2}=0.11\right)$, whereas there was no significant relationship after grouper removal $(F=0.13, \mathrm{df}=1,94, \mathrm{p}=0.71)$. The Date $x$ grouper Removal interaction from the 3-way ANOVA was due to significantly higher abundances of small lobster in grouper removal casitas compared to Control casitas, during the period in which grouper were removed from casitas (Ryan's $Q$ test; Fig. 6B). The Date $\times$ grouper Removal interaction observed for small juvenile lobsters was exactly opposite to the pattern observed for Nassau grouper (compare Figs. 4B \& 6B)

Table 2. Three-way ANOVA table (model I). Effects of sampling Date (averaged over 7 mo before grouper were removed, averaged over 12 mo after grouper were removed), Casita Size (small, large), and grouper Removal (removed, not removed) upon the mean numbers of small spiny lobster (35 to $48 \mathrm{~mm} \mathrm{CL}$ ) per casita. Lobster abundance was logtransformed $(+1)$ to standardize variances

\begin{tabular}{|lccc|}
\hline Source of variation & df & MS & $F$ \\
\hline Date & 1 & 0.18 & $1.83 \mathrm{NS}$ \\
Casita Size & 1 & 0.43 & $4.24 \cdot$ \\
Removal & 1 & 1.34 & $13.21 \cdots$ \\
Date $\times$ Casita Size & 1 & 1.05 & $10.44 \cdots$ \\
Date $\times$ Removal & 1 & 0.84 & $8.30 \cdots$ \\
Casita Size $\times$ Removal & 1 & 0.01 & $0.14 \mathrm{NS}$ \\
Date $\times$ Casita Size $\times$ Removal & 1 & 0.02 & $0.17 \mathrm{NS}$ \\
Error & 144 & 0.10 & \\
NS: $p>0.05 ; " p<0.05, \cdots p<0.005, \cdots p<0.002$ \\
\end{tabular}

\section{Reef fish prey}

The mean abundance of reef fish prey peaked during the late summer and early fall of 1991, regardless of shelter size or whether or not grouper were removed (Fig. 7A, B). Another peak in reef fish abundance was 

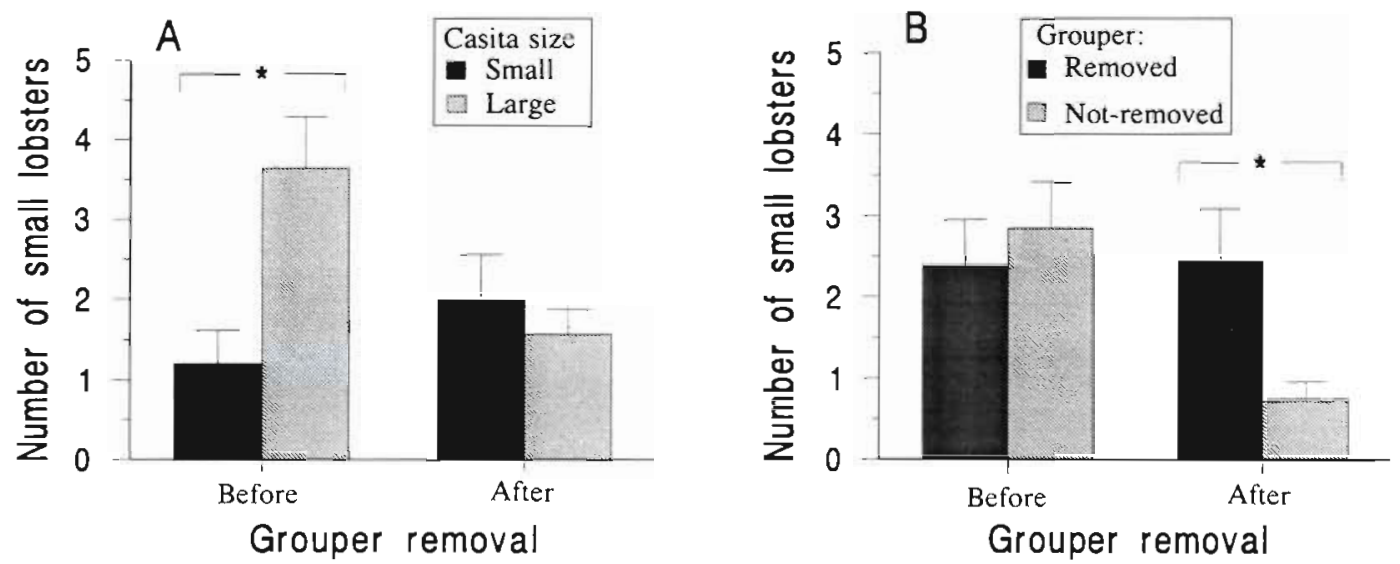

Fig. 6. Effects of sampling Date (averaged over 7 mo before grouper were removed, averaged over 12 mo after grouper were removed) on the number of small lobsters residing in (A) small versus large casitas, and (B) grouper Removal versus Control (not removed) casitas. $N=2$. Values are back transformed means $+1 \mathrm{SE}$. * Treatments that are significantly different at the 0.05 level

observed during the late spring and early summer of 1992 (Fig. 7A, B). Mean reef fish abundance per casita did not vary significantly according to either Date, Casita Size or grouper Removal (3-way ANOVA; all $p>0.08)$. None of the interaction effects were significant (all $p>0.07$ ). The number of reef fish prey species also peaked during the summer of 1991, irrespective of casita size (Fig 7C, D). However, the mean number of
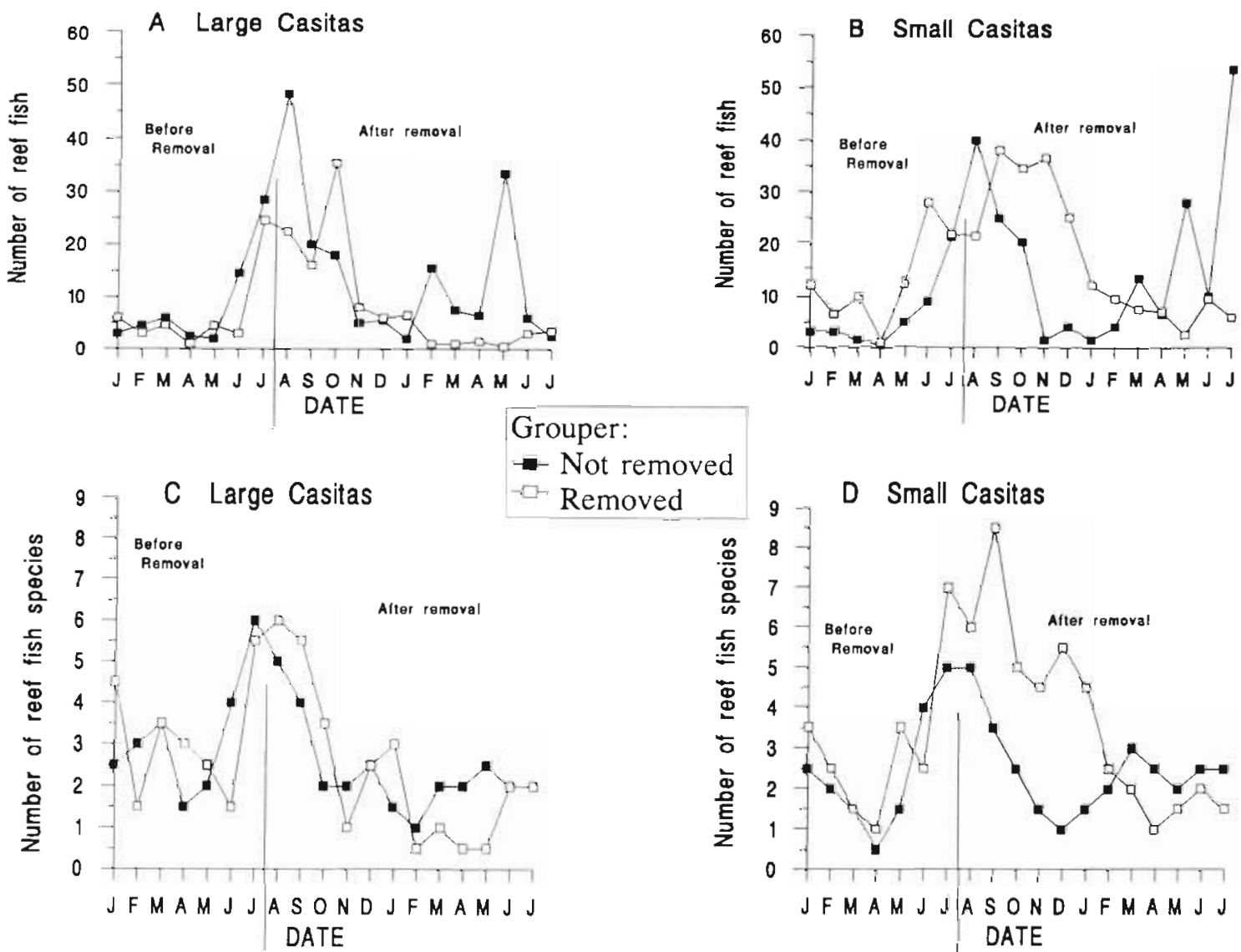

- Not removed Removed

D Small Casitas

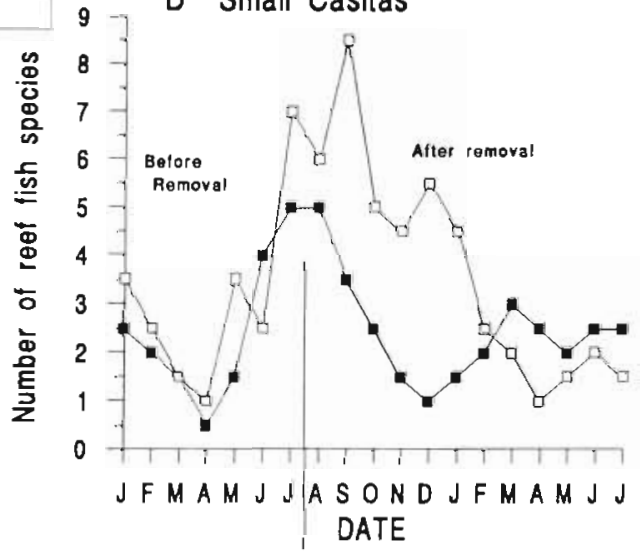

Fig. 7. Effects of sampling Date (7 mo before grouper were removed, 12 mo after grouper were removed), and grouper Removal (not removed, removed) on the mean number of reef fish prey $(11010 \mathrm{~cm} T L)$ residing in (A) large and (B) small casitas, and the mean number of reef fish species residing in (C) large and (D) small casitas. $N=2$. Error bars were eliminated for clarity; see text for significance levels 
Fig. 8. Relationship between reef fish prey abundance $(1$ to $10 \mathrm{~cm}$ TL) and (A) the number of reef fish species, and (B) species evenness. Relationship between medium size reef fish prey abundance ( 4 to $10 \mathrm{~cm} \mathrm{TL}$ ) and (C) the number of medium size reef fish species, and (D) species evenness. $N=96$

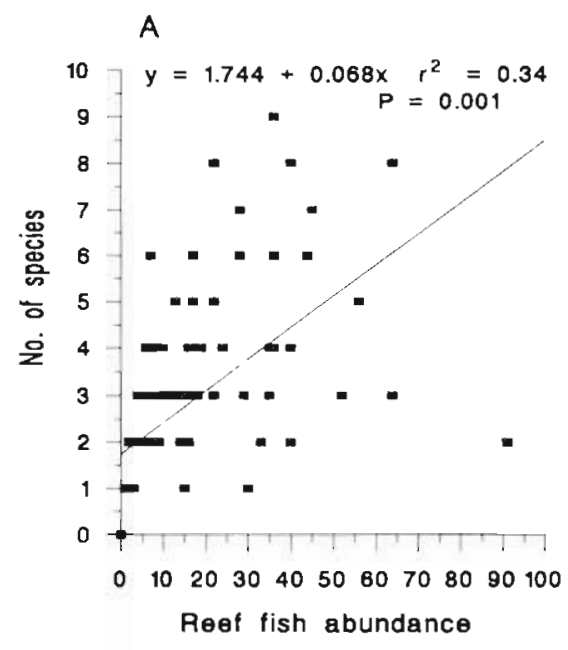

C

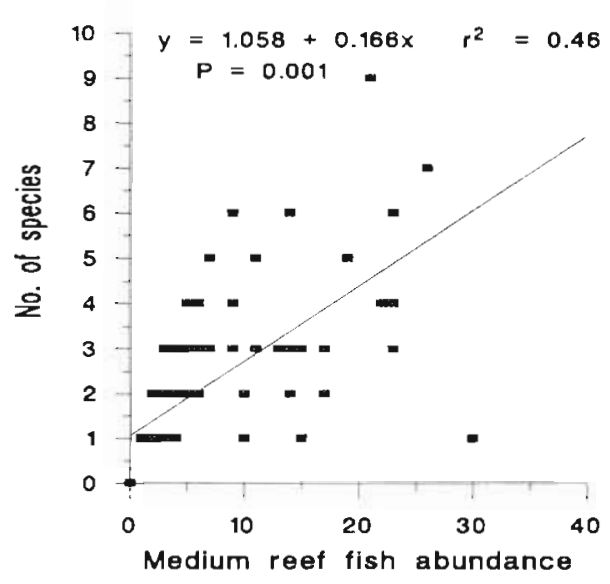

B

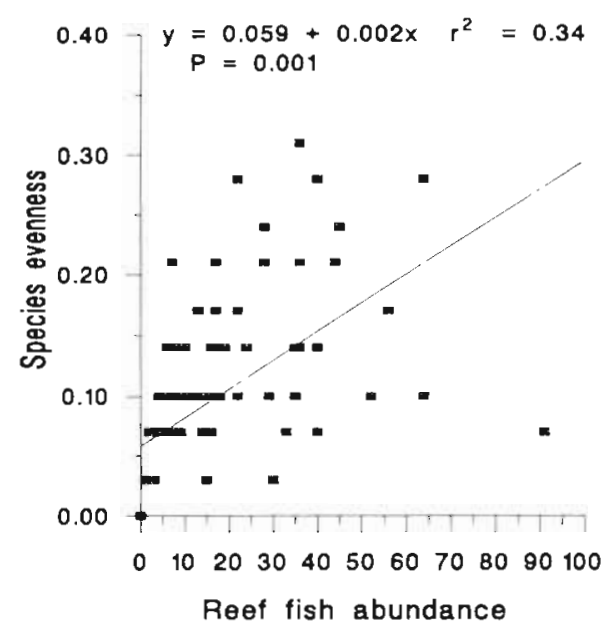

D

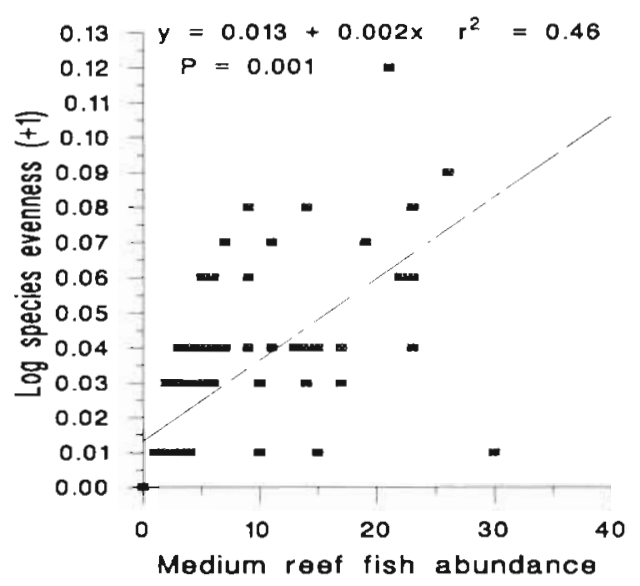

reef fish species and species evenness did not vary according to Date, Casita Size or grouper Removal (3-way ANOVA; all p > 0.15); none of the interaction effects were significant (all $p>0.10$ ). With respect to reef fish abundance, a subsequent power analysis (see Zar 1984, p. 227) indicated that there was adequate statistical power to detect either a Date or Casita Size effect $($ power $=$ ca 95\%), but not a grouper Removal effect (power $=$ ca $10 \%$ ). Similarly, there was inadequate statistical power to detect a Date, Casita Size or grouper Removal effect upon the number of reef fish species and species evenness (power $=\mathrm{ca} 10$ to $40 \%$ ). After grouper removal, there was a positive and significant linear relationship between the number of reeffish prey species and evenness, and the abundance of reef fish per casita (Fig. 8A, B).

We examined the response of medium size reef fish prey because we were concerned that sporadically high recruitment pulses of grunts and parrotfish would overwhelm any patterns due to experimental treatments, which in fact did occur. Monthly patterns in abundance and species richness of medium size reef fish (4 to $10 \mathrm{~cm} \mathrm{TL)} \mathrm{were} \mathrm{highly} \mathrm{variable} \mathrm{with} \mathrm{peaks} \mathrm{in}$ abundance occurring during summer, winter and spring months (Fig 9). This pattern generally reflected that observed for all reef fish prey (compare Figs. 7 \& 9). Neither the abundance nor number of medium reef fish species per casita varied according to any of the main effects (i.e. Date, Casita Size or grouper Removal; 3-way ANOVA: all $p>0.09$ ). However, there were significant Casita Size $\times$ Removal interactions for both fish abundance and species richness response variables (Fig. 10). The interaction was due to significantly higher abundances, number of species, and species evenness of medium fish in small Removal casitas compared to small Control casitas (Ryan's Q test; Fig. 10). No difference was observed between large Removal versus Control casitas (Ryan's $Q$ test). After grouper removal, there was also a positive and significant lin. ear relationship between the number of medium fish prey species and evenness, and the abundance of medium reef fish per casita (Fig. 8C, D). 


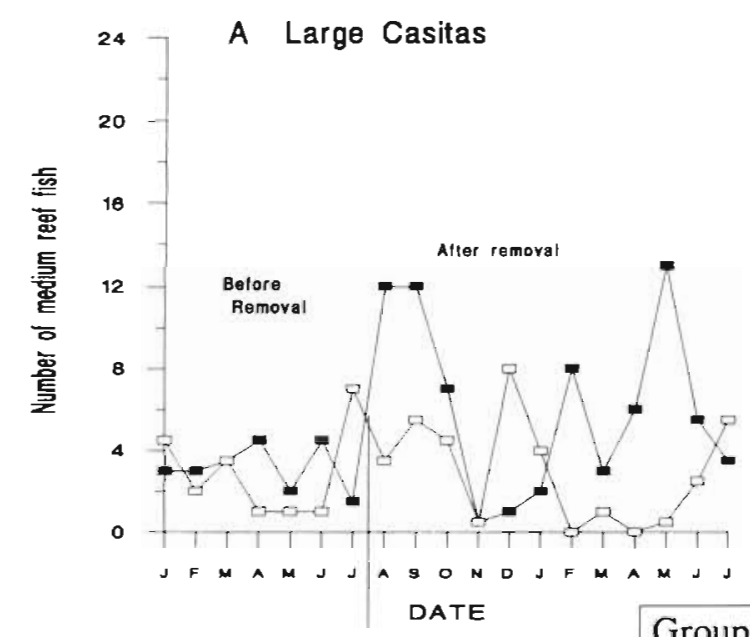

Grouper:

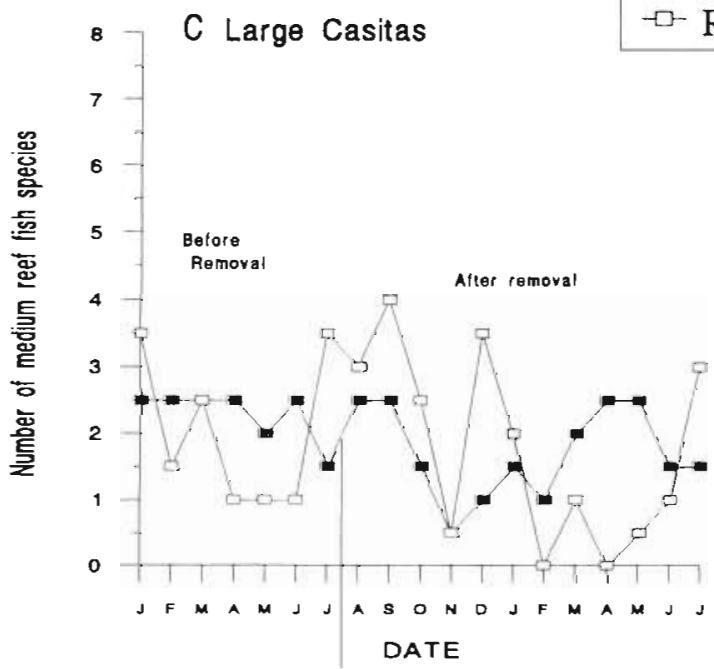

B Small Casitas

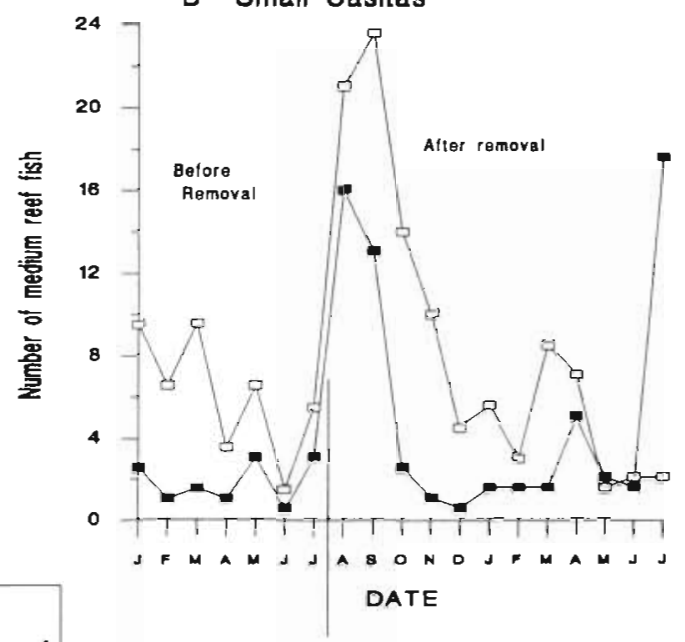

D Small Casitas

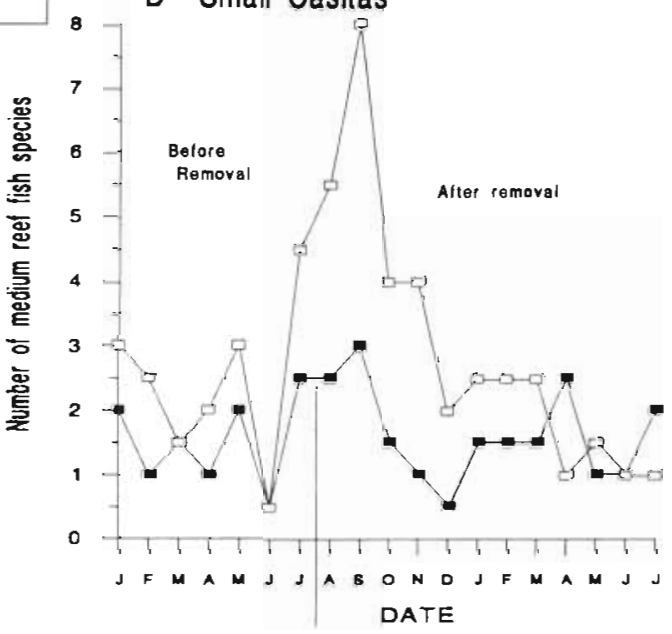

Fig. 9. Effects of sampling Date ( 7 mo before grouper were removed, 12 mo after grouper were removed), and grouper Removal (not removed, removed) on the mean number of medium size reef fish prey (4to $10 \mathrm{~cm} \mathrm{TL}$ ) residing in (A) large and (B) small casitas, and the mean number of reef fish species residing in (C) large and (D) small casitas at the. $N=2$. Error bars were elimınated for clarity; see text for significance levels
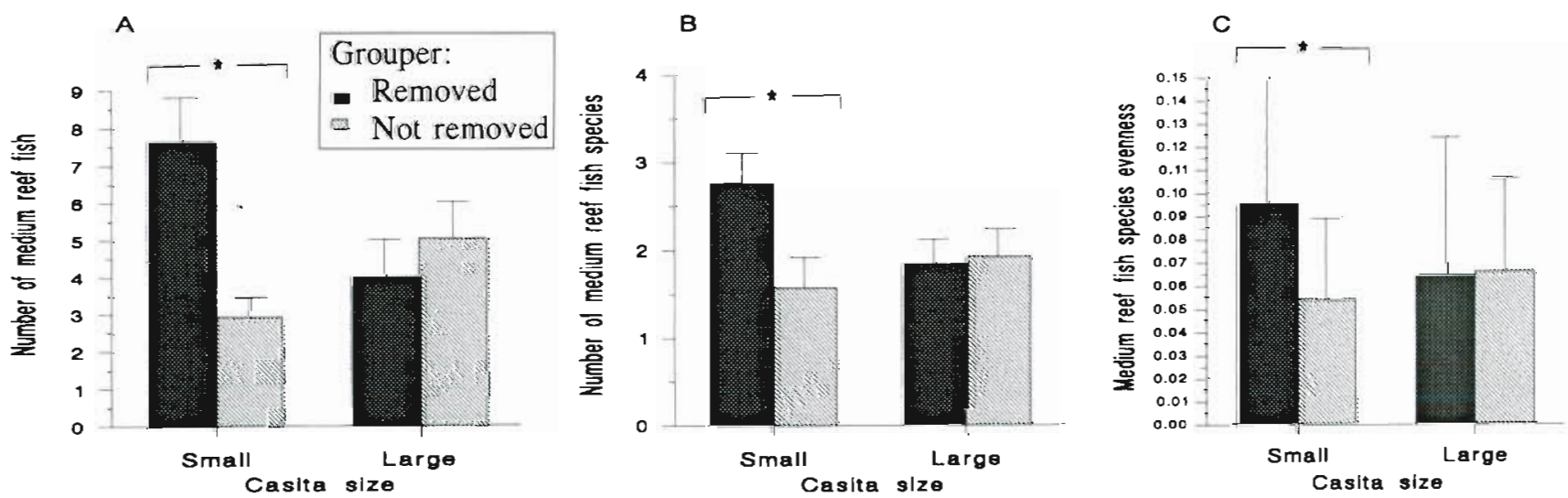

Fig. 10. Effects of grouper Removal (removed, not-removed) and Casita Size (small, large) on the (A) abundance, (B) species richness, and (C) species evenness of medium reef fish prey. Means $+1 \mathrm{SE}$ are displayed. $\mathrm{N}=2$. See text for significance levels 
Relationship between predator and prey abundance

For the 12 mo period in which grouper were removed from certain casitas, there was a negative and significant linear relationship between the number of grouper predators, and 6 of 7 prey response variables: (1) number of small lobsters (Fig. 11A); (2) number of medium reef fish prey (Fig. 11B); (3) number of medium reef fish prey species (Fig 11C); (4) number of reef fish prey species (Fig. 11D); (5) evenness of medium reef fish prey $\left(\mathrm{df}=1,94, \mathrm{p}=0.008, \mathrm{R}^{2}=0.07\right)$; and (6) evenness of reef fish prey $(\mathrm{df}=1,94, \mathrm{p}=0.004$, $\mathrm{R}^{2}=0.08$ ). Although variances for all variables were homoscedastic (either with or without transformation) and the residuals were distributed normally (binomial $z$-test), the regression models explained very little of the variance observed. Nevertheless, there is evidence for a weak but significant negative impact of Nassau grouper abundance on reef fish and spiny lobster abundance, and reef fish species richness.
To determine a posteriori the mechanisms underlying the negative relationship between grouper predator abundance and the number of reef fish prey species, we compared the relative abundance patterns of prey species on 5 to 6 casitas with the highest number of species (and lowest grouper abundance), to those on 5 to 6 casitas with the lowest prey species (and highest grouper abundance) (after Hixon \& Beets 1993). These reefs are indicated by asterisks on Fig. 11C, D, and were chosen because they represented visually distinct groupings. Predatory Nassau grouper appeared to reduce the abundances of all reef fish prey species and medium size prey species in a generalized, nonselective pattern, with no significant difference in the number of rare versus common prey species that were extirpated (Table 3, Mann-Whitney $U$-test, $p>0.05$ in both cases). With the exception of sharpnose puffer Canthigaster rostrata, all rare and common species were either extirpated or less abundant at high grouper abundances (Table 3).
Fig. 11 Relationship between the number of grouper predators and (A) number of small lobsters (B) number of medium size reef fish prey, (C) number of medium size reef fish prey species, and (D) number of reef fish prey species recorded over a 12 mo period after grouper were removed. $\mathrm{N}=96$. Many of these data have the same $x$ and $y$ values, which mask numerous points in some instances. Asterisks denote the most speciose flow grouper abundance) or least speciose (high grouper abundance) casitas. Casitas with asterisks are examined in Table 3
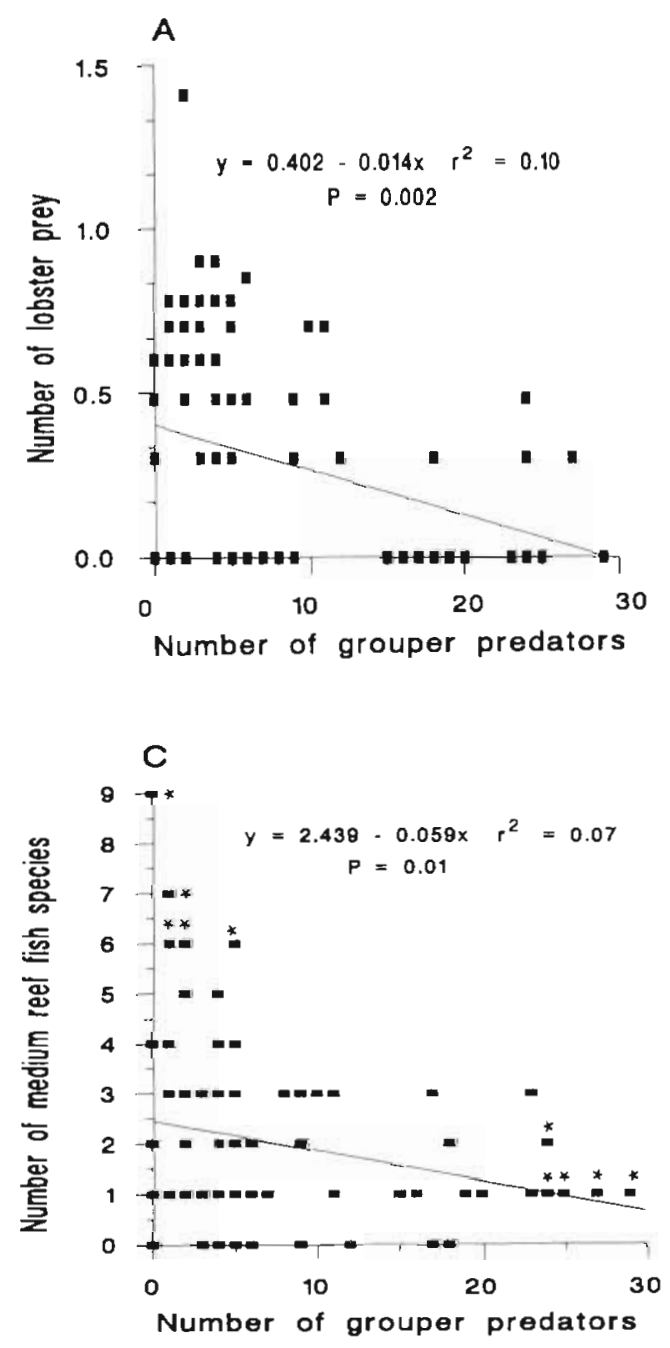
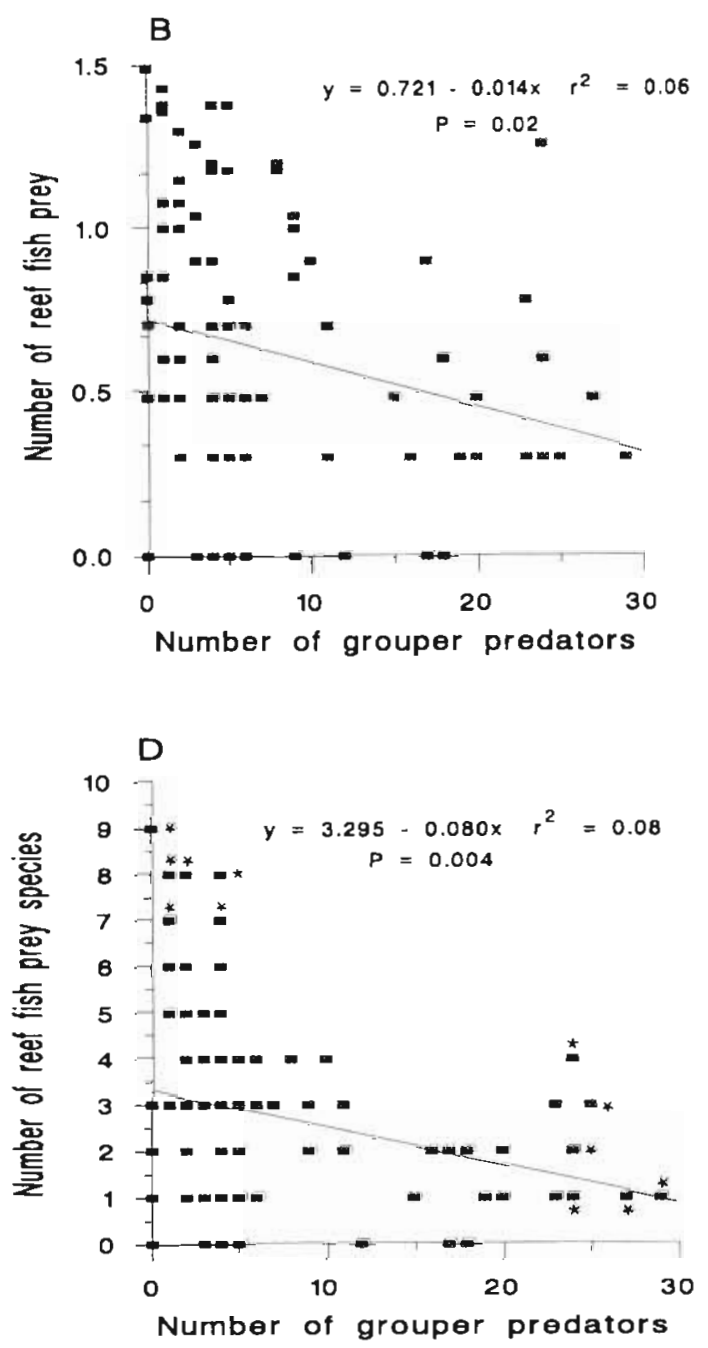
Table 3. Summary of differences in prey species relative abundances between casitas with low grouper predator abundance (high numbers of prey species) and casitas with high grouper predator abundances (low numbers of prey species). Numbers of species extirpated between casitas of high and low grouper abundance were tested by Mann-Whitney $U$-tests. $N=5$ casitas for medium reef fish prey (denoted by asterisks in Fig. 11C). $N=6$ casitas for reef fish prey (denoted by asterisks in Fig. 11D)

\begin{tabular}{|c|c|c|c|c|}
\hline \multirow{2}{*}{$\begin{array}{l}\text { Prey at low } \\
\text { grouper } \\
\text { abundance }\end{array}$} & \multicolumn{4}{|c|}{$\begin{array}{l}\text { No. of prey species at high grouper abundance that } \\
\text { compared to low grouper abundances, were.. }\end{array}$} \\
\hline & Extirpated & $\begin{array}{l}\text { Less } \\
\text { abundant }\end{array}$ & $\begin{array}{l}\text { More } \\
\text { abundant }\end{array}$ & $\begin{array}{c}\text { Not } \\
\text { different }\end{array}$ \\
\hline \multicolumn{5}{|c|}{ Medium size fish prey species } \\
\hline 9 most abundant species & 7 & 1 & 1 & - \\
\hline 9 least abundant species & 9 & 0 & 0 & - \\
\hline \multicolumn{5}{|l|}{ All fish prey species } \\
\hline 9 most abundant species & 7 & 1 & 0 & 1 \\
\hline 9 least abundant species & 9 & 0 & 0 & - \\
\hline
\end{tabular}

\section{DISCUSSION}

The abundance of predatory Nassau grouper and the size of shelters from predation jointly explained the observed distribution and abundance patterns of spiny lobster and reef fish prey inhabiting artificial patch reef habitats in this study. Our results from monthly censuses of 8 artificial patch reefs, containing naturally recruited fish and spiny lobster assemblages over a 19 mo period, identified the importance of predation in reducing prey abundance and species diversity. The abundance of predatory Nassau grouper generally had a negative effect on the abundance of spiny lobster and reef fish prey, and reef fish species richness. However, the effects of shelter size varied according to prey type and the abundance of predatory grouper. In general, the abundance of small spiny lobster, and the abundance and species richness of medium size reef fish (4 to $10 \mathrm{~cm} \mathrm{TL}$ ), was highest in small shelters where grouper were removed.

\section{Interactive effects of shelter size and predators on reef prey}

Spiny lobster prey

Spiny lobster are commercially important marine benthic omnivores that frequently aggregate during the day in crevices of coral and rocky reefs (see review by Lipcius \& Cobb 1994). Gregarious behavior in dens probably enhances individual survivorship because spiny lobsters collectively use their spinose antennae to fend off diurnally active predators (Cobb 1981, Zimmer-Faust \& Spanier 1987). For instance, field experiments demonstrated a positive, significant relationship between survival of tethered juvenile spiny lobster in casitas, and increasing abundance of large conspecifics (Mintz et al. 1994). Moreover, when the potential for lobster gregariousness was high (i.e. high lobster abundance), small spiny lobster preferred to reside gregariously in large shelters with large conspecifics, rather than solitarily in small shelters scaled to their body size (Eggleston \& Lipcius 1992). Conversely, when the potential for gregariousnenss was low (i.e. low lobster abundance), small lobsters preferred to reside in small shelters that were scaled to their body size (Eggleston \& Lipcius 1992). These same tradeoffs in shelter use patterns of juvenile lobster were evident in this study. At the beginning of the study, the potential for gregariousness was relatively high, and there was a positive and significant relationship between the abundance of small lobsters and large conspecifics. During this time small lobsters resided primarily in large casitas Despite the experimental removal of predatory Nassau grouper during the latter half of this study, the overall abundance of Nassau grouper increased whereas the overall abundance of spiny lobster decreased. During this time, small spiny lobster exhibited a shift in shelter use from large to small casitas. The abundance of small lobsters was highest in small casitas from which Nassau grouper were experimentally removed.

The negative, significant relationship between the abundance of predatory Nassau grouper and small spiny lobster may have been due to a combination of factors including: (1) predation by resident grouper; (2) agonistic interactions between grouper and lobster; or (3) both. Considering predation separately, spiny lobster have been reported in the stomachs of Nassau grouper collected in the Virgin Islands and Puerto Rico (Randall 1965), and we have observed Nassau grouper inhabiting casitas to easily ingest whole, small juvenile lobster (D. Eggleston pers. obs.). Moreover, small spiny lobster (30 to $45 \mathrm{~mm} \mathrm{CL}$ ) suffered approximately $80 \%$ predation-induced mortality when tethered to casitas at Sugar Cay Bay (D. Eggleston unpubl. data). Thus, we suggest that Nassau grouper $>20.0 \mathrm{~cm}$ TL are important predators of small, juvenile lobsters, and that the negative relationship between grouper abundance and small lobster abundance is due, in part, to predation. However, Panulirus argus exhibits strong tail-flipping responses to escape predatory attack, and often become nomadic and leave an area when disturbed by predators (Herrnkind 1980, Kanciruk 1980). Thus, we suggest that, as juvenile spiny lobster migrate from macroalgae-dominated settlement and early juvenile nursery habitats in mangrove creeks west of Sugar 
Cay Bay (Fig. 1) to patch reef habitats in Sugar Cay Bay, small lobsters ( $<45 \mathrm{~mm}$ CL) suffer high predationinduced mortality in patch reef habitats due to high numbers of resident Nassau grouper, and larger juveniles become nomadic and emigrate to other areas due to agonistic encounters with resident grouper

\section{Reef fish prey}

Our experimental results indicate that the joint effects of predator abundance and shelter size were significant determinants of reef fish prey species abundance and richness depending upon whether or not new recruits (fish $<1$ to $3 \mathrm{~cm}$ TL) were considered (see also Hixon \& Beets 1993). When we assessed the effects of predator abundance on all reef fish prey ( 1 to $10 \mathrm{~cm} \mathrm{TL}$ ), we were unable to detect any significant effects on prey abundance or species richness ( $S$ and $E$ ) due to low statistical power. This result may have been due to a combination of factors including: (1) predator swamping by large pulses of parrotfish and grunt recruits; (2) preference by large Nassau grouper ( $>20 \mathrm{~cm}$ TL) for fish prey $>4 \mathrm{~cm} \mathrm{TL;} \mathrm{and} \mathrm{(3)} \mathrm{high} \mathrm{vari-}$ ability in reef fish prey numbers combined with low sample size. Considering only medium size reef fish prey $(4$ to $10 \mathrm{~cm} \mathrm{TL})$, there was also no effect of grouper removal on total abundance and species richness in large casitas. These results suggest that medium size reef fish prey residing in large casitas without resident Nassau grouper may be vulnerable to other piscivores inhabiting large casitas. Previous observations indicate that the size range, maximum size, and species diversity of predators increases with casita size, thereby imposing higher predation intensity in larger casitas (Eggleston et al. 1990). However, the total abundance and species richness of medium size reef fish prey (4 to $10 \mathrm{~cm}$ TL) was enhanced in small casitas from which grouper were removed. This pattern suggests that medium size reef fish were not simply choosing to reside in small shelters, but instead were surviving better in small shelters that had reduced predation pressure from Nassau grouper.

Several studies have monitored reef fish recruitment and survivorship to reefs of different hole sizes and predator densities (Shulman 1985, Hixon \& Beets 1989. 1993) or reef morphologies (Shulman 1984, Clarke 1988) For example, abundance of small reef fishes inhabiting artificial patch reefs in St. Thomas, U.S. Virgin Islands, was correlated positively with the number of holes near their body sizes (Hixon \& Beets 1989, 1993). In St. Croix, USVI, juveniles of most reef fish species were more abundant on coral species such as Porites porites, which provide a large number of small crevices between branches, compared to other coral morphologies (Shulman 1984). The results from this and previous studies (Shulman 1984, Hixon \& Beets $1989,1993)$ suggest that under conditions of refuge limitation an absence of appropriately scaled refuges can limit the abundance and species richness of reef fish prey. Moreover, the negative correlation between the abundance of predatory Nassau grouper and medium size reef fish prey observed in this study is similar to the negative relationship observed between the abundance of resident predators and both reef fish (Hixon \& Beets 1989, 1993) and spiny lobster (Eggleston et al. 1992) prey in Caribbean reef systems.

\section{General community-level effects of predation}

Our study revealed that after grouper were experimentally removed from selected artificial patch reefs there was a significant negative relationship between the number of Nassau grouper predators and medium size reef fish (4 to $10 \mathrm{~cm} T L$ ) species richness ( $S$ and $E$ ) (Fig. 11). These results suggest that, despite considerable variability in recruitment, local reef fish species richness was determined, at least in part, by Nassau grouper predation intensity. There was no evidence that Nassau grouper played a 'keystone predator' role (sensu Paine 1974) by enhancing prey diversity at high predator abundances, either by increasing prey evenness, or by allowing new species to enter the system.

Several conceptual models have been proposed to explain the phenomena that local prey diversity decreases monotonically as predation intensity increases from zero (see review by Hixon 1986). The first mechanism predicts that predators non-selectively reduce all prey populations in proportion to their initial relative abundances (Van Valen 1974), whereas the second mechanism predicts that disproportionate predation on competitively subordinate species decreases species diversity (Lubchenco 1978). The Van Valen (1974) model of non-selective predation was recently hypothesized for piscivorous reef fishes inhabiting patch reefs in St. Thomas, USVI (Hixon \& Beets 1993). Our results indicate that Nassau grouper in the Bahamas also reduce prey abundances in a generalized, non-selective pattern, with no difference in the number of rare versus common prey species that were extirpated. With the exception of the sharpnose puffer Canthigaster rostrata, all rare and common species were either extirpated or less abundant at high grouper abundances. Members of the genus Canthigaster are among the most highly toxic of reef fishes (Gladstone 1987), which suggests that southern puffers may not be a potential prey item for Nassau grouper. Interestingly, the same observation was made for this species in St. Thomas, USVI (Hixon \& Beets 1993), suggesting that the tox- 
icity of sharpnose puffer may result in them being avoided by a wide range of piscivores.

We conclude that juvenile Nassau grouper inhabiting certain patch reefs at Sugar Cay Bay produce a general predatory impact, whereby predation reduces prey abundance and diversity in proportion to their initial relative abundances. Thus, in habitats where refuges appear to be limiting, predation by Nassau grouper appears to be a critical determinant of crustacean and reef fish distribution, abundance and species diversity.
Acknowledgements. We are very grateful to J Chaves, $\mathrm{L}$ Coba, D. Fuss, and members of the crustacean ecology program at the Virginia Institute of Marine Science for field assistance. Tremendous logistical support was provided by the staff of the Caribbean Marine Research Center. We also thank $M$. Carr for advice on tagging grouper, D. Nadeau and $M$. Grott for help in data reduction, and D. Boos for statistical advice. The manuscript was improved by comments from $M$. Hixon and 3 anonymous referees. This work was funded by the Caribbean Marine Research Center, National Undersea Research Center of the National Oceanic and Atmospheric Association; North Carolina State University; and the College of William and Mary.

Appendix 1. Mean number of fish by species per casita census. Note that new recruits of grunts and parrotfishes could not be identified to species until they exceeded $3 \mathrm{~cm}$ in total length. Guild assignments (e.g. herbivore, piscivore) generally follow species-specific criteria in Hixon \& Beets (1993). Reference to 'with' and 'w/o' refers to grouper present and absent, respectively

\begin{tabular}{|c|c|c|c|c|c|c|c|}
\hline \multirow{3}{*}{$\begin{array}{l}\text { Family } \\
\text { Species }\end{array}$} & \multirow[t]{3}{*}{ Guild $^{\mathrm{d}}$} & \multicolumn{6}{|c|}{ Mean no. fish per casita per census } \\
\hline & & \multicolumn{3}{|c|}{ Pre-removal } & \multicolumn{3}{|c|}{ Post-removal } \\
\hline & & $\begin{array}{l}\text { Small } \\
\text { casita } \\
\text { (with) }\end{array}$ & $\begin{array}{l}\text { Large } \\
\text { casita } \\
\text { (with) }\end{array}$ & $\begin{array}{l}\text { Small } \\
\text { casita } \\
\text { (w/o) }\end{array}$ & $\begin{array}{l}\text { Large } \\
\text { casita } \\
(w / 0)\end{array}$ & $\begin{array}{l}\text { Small } \\
\text { casita } \\
\text { (with) }\end{array}$ & $\begin{array}{l}\text { Large } \\
\text { casita } \\
\text { (with) }\end{array}$ \\
\hline \multicolumn{8}{|l|}{ Acanthuridae: } \\
\hline Acanthurus bahanus (ocean surgeonfish) & $\mathrm{H}$ & 0.18 & 0.39 & 0.04 & 0.17 & - & 0.83 \\
\hline Acanthurus chirurgus (doctorfish) & $\mathrm{H}$ & - & 0.29 & 0.08 & 0.42 & 0.13 & 0.33 \\
\hline Acanthurus coeruleus (blue tang) & $\mathrm{H}$ & - & - & - & - & 0.08 & 0.04 \\
\hline \multicolumn{8}{|l|}{ Antennariidae: } \\
\hline Histrio histrio (sargassumfish) & M & 0.29 & - & - & - & - & - \\
\hline \multicolumn{8}{|l|}{ Apogonidae: } \\
\hline Apogon spp. (cardinalfish) & $P$ & - & - & - & 0.04 & - & - \\
\hline \multicolumn{8}{|l|}{ Aulostomidae: } \\
\hline Aulostomus maculatus (trumpetfish) & $F, T$ & - & 0.04 & - & 0.04 & - & \\
\hline \multicolumn{8}{|l|}{ Balistidae: } \\
\hline Balistes vetula (queen triggerfish) & $M, L$ & - & 0.04 & - & - & 0.04 & - \\
\hline \multicolumn{8}{|l|}{ Carangidae: } \\
\hline Caranx bartholomaei (yellow jack) & F,L,T & 0.35 & - & 0.88 & 0.25 & - & - \\
\hline Caranx fusus (blue runner) & $F, L, T$ & 1.25 & - & - & 0.04 & - & - \\
\hline Caranx ruber (bar jack) & $F, L, T$ & 0.43 & 1.79 & 0.04 & 0.04 & 0.08 & - \\
\hline \multicolumn{8}{|l|}{ Chaetodontidae: } \\
\hline Chaetodon aculeatus (longsnout butterflyfish) & M & 0.07 & 0.04 & - & - & - & 0.04 \\
\hline Chaetodon capistratus (foureye butterflyfish) & M & 0.04 & 0.25 & - & - & - & - \\
\hline Chaetodon oscellatus (spotfin butterflytish) & M & 0.07 & 0.11 & - & - & - & 0.08 \\
\hline \multicolumn{8}{|l|}{ Diodontidae: } \\
\hline Diodon hystrix (porcupinefish) & M & - & - & - & 0.08 & - & 0.08 \\
\hline \multicolumn{8}{|l|}{ Gerreidae: } \\
\hline Gerres cinereus (yellowfin mojarra) & M & 5.00 & - & - & - & - & - \\
\hline \multicolumn{8}{|l|}{ Gobiidae: } \\
\hline Coryphopterus glaucofraenum (bridled goby) & $M$ & - & - & 0.33 & 0.33 & 0.71 & 0.04 \\
\hline \multicolumn{8}{|l|}{ Haemulidae (Pomadasyidae): } \\
\hline Haemulon aurolineatum (tomtate) & M & 0.71 & 0.32 & 1.45 & 0.67 & 1.54 & 0.25 \\
\hline Haemulon flavolineatum (French grunt) & $\mathrm{M}$ & 0.64 & 0.39 & 1.46 & 0.29 & 1.92 & 0.17 \\
\hline Haemulon macrostomum (Spanish grunt) & $\mathrm{M}$ & 0.11 & - & - & - & - & - \\
\hline Haemulon plumieri (white grunt) & $M$ & 0.32 & 0.14 & 1.46 & 1.20 & 1.00 & 0.25 \\
\hline Haemulon sciurus (bluestriped grunt) & M,L & 0.93 & 0.14 & - & - & 0.46 & 0.04 \\
\hline Haemulon spp. recruits & M & 3.46 & 2.14 & 7.79 & 3.33 & 5.00 & 3.75 \\
\hline \multicolumn{8}{|l|}{ Holocentridae: } \\
\hline Holocentrus ascensionis (longjaw squirrelfish) & F,T & - & 0.04 & - & 0.04 & - & - \\
\hline \multicolumn{8}{|l|}{ Labridae: } \\
\hline Bodianus rufus (Spanish hogfish) & $M, L$ & - & - & 0.04 & - & - & - \\
\hline Halichoeres bivittatus (slippery dick) & $M, T$ & 2.61 & 0.14 & 0.21 & 0.25 & 1.50 & 0.42 \\
\hline Halichoeres maculipinna (clown wrasse) & M.T & 0.07 & 0.04 & 0.08 & 0.04 & 1.29 & 0.08 \\
\hline Halichoeres poeyi (blackear wrasse) & M & 0.14 & - & - & - & - & - \\
\hline Thalassoma bifasciatum (bluehead wrasse) & M & 0.11 & 0.21 & 0.33 & 0.04 & 0.71 & 0.33 \\
\hline
\end{tabular}


Appendix 1 (continued)

\begin{tabular}{|c|c|c|c|c|c|c|c|}
\hline \multirow{3}{*}{$\begin{array}{l}\text { Family } \\
\text { Species }\end{array}$} & \multirow[t]{3}{*}{ Guild" } & \multicolumn{6}{|c|}{ Mean no. fish per casita per census } \\
\hline & & \multicolumn{3}{|c|}{ Pre-removal } & \multicolumn{3}{|c|}{ Post-removal } \\
\hline & & $\begin{array}{l}\text { Small } \\
\text { casita } \\
\text { (with) }\end{array}$ & $\begin{array}{l}\text { Large } \\
\text { Casita } \\
\text { (with) }\end{array}$ & $\begin{array}{l}\text { Small } \\
\text { Casita } \\
(w / 0)\end{array}$ & $\begin{array}{l}\text { Large } \\
\text { casita } \\
\text { (w/o) }\end{array}$ & $\begin{array}{l}\text { Small } \\
\text { casita } \\
\text { (with) }\end{array}$ & $\begin{array}{l}\text { Large } \\
\text { casita } \\
\text { (with) }\end{array}$ \\
\hline \multicolumn{8}{|l|}{ Lutjanıdae: } \\
\hline Lutjanus analis (mutton snapper) & $F, L, T$ & 0.43 & - & - & - & - & - \\
\hline Lutjanus apodus (schoolmaster snapper) & F, L & - & 0.04 & - & - & - & 0.17 \\
\hline Lutjanus mahogoni (mahogony snapper) & $\mathrm{F}$ & 0.29 & 0.04 & - & - & 0.08 & - \\
\hline Lutjanus synagris (lane snapper) & F,L & - & - & - & - & 1.90 & 0.04 \\
\hline Ocyurus chrysurus (yellowtall snapper) & $\mathrm{F}, \mathrm{P}$ & 1.89 & 0.14 & 0.04 & - & 0.33 & 0.54 \\
\hline \multicolumn{8}{|l|}{ Mullidae: } \\
\hline Pseudopeneus maculatus (spotted goatfish) & $\mathrm{M}, \mathrm{T}$ & - & - & - & - & 0.08 & 0.04 \\
\hline \multicolumn{8}{|l|}{ Muraenidae: } \\
\hline Gymnothorax moringa (spotted moray eel) & F, L & 0.04 & 0.07 & - & 0.04 & - & - \\
\hline \multicolumn{8}{|l|}{ Ostraciidae: } \\
\hline Lactophrys trigonus (trunkfish) & $M, L$ & - & - & - & 0.04 & - & - \\
\hline \multicolumn{8}{|l|}{ Pomacanthidae: } \\
\hline Holocanthus ciliaris (queen angelfish) & M & - & 0.04 & - & - & - & 0.04 \\
\hline Holocanthus tricolor (rock beauty) & $\mathrm{M}$ & - & 0.04 & - & - & - & 0.04 \\
\hline Pomacanthus arcuatus (gray angelfish) & M & - & 0.04 & 0.17 & 0.54 & 0.04 & 0.42 \\
\hline \multicolumn{8}{|l|}{ Pomacentridae: } \\
\hline Stegastes leucostictus (beaugregory) & $\mathrm{H}$ & 0.46 & 0.46 & 0.25 & 0.33 & 0.79 & 0.25 \\
\hline Stegastes planifrons (threespot damselfish) & $\mathrm{H}$ & 0.04 & - & - & - & - & - \\
\hline Stegastes variabilis (cocoa damselfish) & $\mathrm{H}$ & 0.04 & - & - & - & - & - \\
\hline \multicolumn{8}{|l|}{ Scaridae: } \\
\hline Scarus vetula (queen parrotfish) & $\mathrm{H}$ & 0.18 & 0.43 & 1.46 & 1.25 & 1.67 & 0.75 \\
\hline Sparisoma aurofrenatum (redband parrotfish) & $\mathrm{H}$ & 0.07 & 0.18 & 0.04 & - & - & - \\
\hline Sparisoma radians (bucktooth parrotfish) & $\mathrm{H}$ & 0.12 & - & - & - & - & - \\
\hline Sparisoma viride (stoplight parrotfish) & $\mathrm{H}$ & - & - & - & 0.21 & - & 0.04 \\
\hline Sparisoma spp./Scarus spp. recruits & $\mathrm{H}$ & 0.71 & 1.43 & 0.88 & 2.63 & 0.83 & 0.71 \\
\hline \multicolumn{8}{|l|}{ Sciaenidae: } \\
\hline Equetus acuminatus (highhat) & M & 0.11 & - & - & - & 0.04 & - \\
\hline \multicolumn{8}{|l|}{ Serranidae: } \\
\hline Epinephelus striatus (Nassau grouper) & F, L & 1.50 & 6.96 & 2.13 & 3.58 & 9.25 & 14.0 \\
\hline Epinephelus fulvus (coney) & F & 0.07 & - & - & - & - & - \\
\hline \multicolumn{8}{|l|}{ Sparidae: } \\
\hline Calamus bajonado (jolthead porgy) & $L, F, T$ & 0.04 & 0.04 & - & 0.13 & 0.17 & - \\
\hline \multicolumn{8}{|l|}{ Sphyraenidae: } \\
\hline Sphyraena barracuda (great barracuda) & $F, L, T$ & 0.11 & 0.04 & 0.04 & 0.04 & 0.04 & 0.04 \\
\hline \multicolumn{8}{|l|}{ Tetraodontidae: } \\
\hline Canthigaster rostrata (sharpnose puffer) & M & - & - & - & - & 0.08 & - \\
\hline Mean total number of fish & & 22.0 & 16.6 & 26.5 & 26.7 & 22.9 & 13.9 \\
\hline Mean total number of species & & 36 & 31 & 22 & 28 & 28 & 29 \\
\hline
\end{tabular}

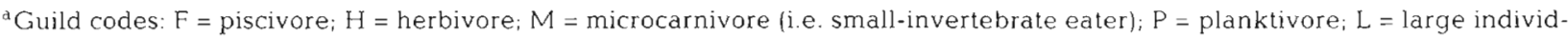
uals $>15 \mathrm{~cm}$ TL; $\mathrm{T}=$ transient (i.e. non-resident)

\section{LITERATURE CITED}

Beets J, Hixon MA (1994) Distribution, persistence, and growth of groupers (Pisces: Serranidae) on artificial and natural patch reefs in the Virgin Islands. Bull Mar Sci $55: 470-483$

Belovsky GE, Slade JB (1993) The role of vertebrate and invertebrate predators in a grasshopper community. Oikos 68:193-201

Bock CE, Bock JH, Grant MC (1992) Effects of bird predation on grasshopper densities in an Arizona grassland. Ecology $73: 1706-1717$
Bohnsack JA, Bannerot SP (1986) A stationary visual census technique for quantitatively assessing community structure of coral reef fishes. NOAA Tech Rep Nat Mar Fish Ser $41: 1-15$

Caddy JF (1986) Modelling stock-recruitment processes in Crustacea: some practical and theoretical perspectives. Can J Fish Aquat Sci 43:2330-2344

Caddy JF, Campbell A (1986) Summary of session 9: summary of research recommendations. Can J Fish Aquat Sci 43 $2394-2396$

Caddy JF, Stamatopoulos C (1990) Mapping growth and mortality rates of crevice-dwelling organisms onto a perfo- 
rated surface: the relevance of 'cover' to the carrying capacity of natural and artificial habitats. Estuar Coast Shelf Sci 31:87-106

Caley MJ (1993) Predation, recruitment and the dynamics of communities of coral-reef fishes. Mar Biol 117:33-43

Carr MH, Hixon MA (1995) Predation effects on early postsettlement survivorship of coral-reef fishes. Mar Ecol Prog Ser 124:31-42

Clarke RD (1.988) Chance and order in determining fishspecies composition on small coral patches. J Exp Mar Biol Ecol 115:197-212

Clavijo IE, Yntema JA, Ogden JC (1980) An annotated list of the fishes of St. Croix, U.S. Virgin Islands, 2nd edn. West Indies Laboratory, St. Croix, U.S. Virgin Islands

Cobb JS (1981) Behaviour of the western Australian spiny lobster, Panulirus cygnus George, in the field and laboratory. Aust J Mar Freshwat Res 31:399-409

Colin PL (1992) Reproduction of the Nassau grouper Epinephelus striatus (Pisces: Serranidae) and its relationship to environmental conditions. Environ Biol Fish 34:357-377

Connell JH (1961) Effects of competition, predation by Thais lapillus and other factors on natural populations of the barnacle Balanus balanoides. Ecol Monogr 31:61-104

Connell JH (1.975) Some mechanisms producing structure in natural communities: a model and evidence from field experiments. In: Cody ML, Diamond JM (eds) Ecology and evolution of communities. Belknap-Harvard University Press, Cambridge, MA, p 460-490

Day RW, Quinn GP (1989) Comparisons of treatments after an analysis of variance in ecology. Ecol Monogr 59:433-463

Dayton PK (1971) Competition, disturbance, and community organization: the provision and subsequent utilization of space in a rocky intertidal community. Ecol Monogr 41. 351-389

Doherty PJ (1981) Coral reef fishes: recruitment-limited assemblages? Proc 4th Int Coral Reef Symp 2:465-470

Doherty PJ (1991) Spatial and temporal patterns in recruitment. Sale PF (ed) The ecology of fishes on coral reefs. Academic Press, San Diego, p 261-293

Doherty PJ, Sale PF (1985) Predation on juvenile coral reef fishes: an exclusion experiment. Coral Reefs 4:225-234

Eggleston DB (1995) Recruitment in Nassau grouper Epinephelus striatus: post-settlement abundance, microhabitat features, and ontogenetic habitat shifts. Mar Ecol Prog Ser 124:9-22

Eggleston DB, Armstrong DA (1995) Pre-and post-settlement determinants of estuarine Dungeness crab recruitment. Ecol Monogr 65:193-216

Eggleston DB, Grover JJ, Lipcius RN (1998) Ontogenetic diet shifts in Nassau grouper: trophic linkages and predatory impact. Bull Mar Sci 62: in press

Eggleston DB, Lipcius RN (1992) Shelter selection by spiny lobster under variable predation risk, social conditions, and shelter size. Ecology 73:992-1011

Eggleston DB, Lipcius RN, Miller DL (1992) Artificial shelters and survival of Caribbean spiny lobster Panulirus argus: spatial, habitat and lobster size effects. Fish Bull US 90: $691-702$

Eggleston DB, Lipcius RN, Miller DL, Coba L (1990) Shelter scaling regulates survival of Caribbean spiny lobster Panulirus argus. Mar Ecol Prog Ser 62:79-88

Forrester GE (1990) Factors influencing the juvenile demography of a coral reef fish. Ecology 71:1666-1681

Forrester GE (1994) Influences of predatory fish on the drift dispersal and local density of stream insects. Ecology 75 : $1208-1218$

Gladstone W (1987) The eggs and larvae of the sharpnose puffer Canthigaster valentini (Pisces: Tetraodontidae) are unpalatable to other reef fishes. Copeia 1987:227-230

Heck, KL, Weinstein MP (1989) Feeding habits of juvenule reef fishes associated with Panamanian seagrass meadows. Bull Mar Sci 45:629-636

Herrnkind WF (1980) Spiny lobsters: patterns of movement In: Cobb JS, Phillips BF (eds) The biology and management

of lobsters, Vol I. Academic Press, New York, p 349-407

Hixon MA (1986) Fish predation and local prey diversity. In: Simenstad CA, Cailliet GM (eds) Contemporary studies on fish feeding. Junk, Dordrecht, p 235-257

Hixon $M$ (1991) Predation as a process structuring coral reef fish communities. In: Sale PF (ed) The ecology of fishes on coral reefs. Academic Press, San Diego, p 475-508

Hixon M, Beets JP (1989) Shelter characteristics and Caribbean fish assemblages: experiments with artificial reefs. Bull Mar Sci 44:666-680

Hixon M. Beets JP (1993) Predation, prey refuges, and the structure of coral-reef fish assemblages. Ecol Monogr 63 $77-101$

Joern A (1992) Variable impact of avian predation on grasshopper assemblies in sandhills grassland. Oikos 64 $458-463$

Jones GP (1991) Postrecruitment processes in the ecology of coral reef fish populations; a multifactorial perspective. In: Sale PF (ed) The ecology of fishes on coral reefs. Academic Press, San Diego, p 294-328

Kanciruk P (1980) Ecology of juvenile and adult Palinuridae (spiny lobsters). In: Cobb JS, Phillips BF (eds) The biology and management of lobsters, Vol I. Academic Press, New York, p 59-96

Kingsford MJ (1992) Spatial and temporal variation in predation on reef fishes by coral trout (Plectropomus leopardis, Serranidae) Coral Reefs 11:193-198

Kneib RT (1988) Testing for indirect effects of predation in an intertidal soft-bottom community. Ecology 69:1795-1805

Lipcius RN, Cobb JS (1994) Introduction: ecology and fishery biology of spiny lobsters. In: Phillips BF, Cobb JS, Kittaka $\mathrm{J}$ (eds) Spiny lobster management. Fishing News Books, Blackwell Scientific, Oxford, p 1-30

Lubchenco J (1978) Plant species diversity in a marine intertidal community: importance of herbivore food preference and algal competitive abilities. Am Nat 112:23-39

Magurran AE (1988) Ecological diversity and its measurement. Princeton University Press, Princeton, NJ, p 179

Menge BA (1976) Organization of the New England rocky intertidal community: role of predation, competition, and environmental heterogeneity. Ecol Monogr 46:355-393

Mintz JD, Lipcius RN, Eggleston DB, Seebo MS (1994) Survival of juvenile Caribbean spiny lobster: effects of shelter size, geographic location and concpecific abundance. Mar Ecol Prog Ser 112:255-266

Paine RT (1974) Intertidal community structure. Experimenta studies on the relationship between a dominant competitor and its principal predator. Oecologia 15:93-120

Parrish JD (1989) Fish communities of interacting shallowwater habitats in tropical oceanic regions. Mar Ecol Prog Ser 58:143-160

Peitgen $H$, Saupe D (1988) The science of fractal images. Springer-Verlag Inc, New York

Peterson CH (1982) The importance of predation and intraand interspecific competition in the population biology of two infaunal suspension feeding bivalves, Protothaca staminea and Chione undatella. Ecol Monogr 52:437-475

Pielou EC (1966) Species diversity and pattern diversity in the study of ecological succession. J Theor Biol 10:370-383 
Posey MH, Hines AH (1991) Complex predator-prey interactions within an estuarine benthic community. Ecology 72 : 2155-2169

Randall JE (1965) Food habits of the Nassau grouper (Epinephelus striatus). Assoc Isl Mar Lab Caribb 6:13-16

Reaka ML (1985) Interactions between fishes and motile benthic invertebrates on reefs: the significance of motility vs. defensive adaptations. Proc 5th Int Coral Reef Congr 5 : $439-444$

Robertson DR (1992) Patterns of lunar settlement and early recruitment in Caribbean reef fishes at Panama. Mar Biol 114:527-537

Roughgarden J (1974) Species packing and competition function with illustrations from coral reef fish. Theor Pop Biol 5 $163-186$

Sale PF (1974) Mechanisms of coexistence in a guild of territorial fishes at Heron Island. Proc 2nd Int Coral Reef Symp $1: 193-206$

Sale PF (1975) Patterns of use of space in a guild of territorial reef fishes. Mar Biol 29:89-97

Shpigel M. Fishelson L (1991) Experimental removal of piscivorous groupers of the genus Cephalopholis (Serranidae) from coral habitats in the Gulf of Aqaba (RedSea). Environ Biol Fish 31:131-138

Shulman MJ (1984) Resource limitation and recruitment patterns in a coral reef fish assemblage. J Exp Mar Biol Ecol $74: 85-109$

Shulman MJ (1985) Recruitment of coral reef fishes: effects of distribution of predators and shelter. Ecology 66: $1056-1066$

Shulman MJ, Ogden JC (1987) What controls tropical reef fish populations: recruitment or benthic mortality? An example in the Caribbean reef fish Haemulon flavolineatum. Mar Ecol Prog Ser 39:233-242

Sih A. Crowley P, McPeek M1, Petranka J (1985) Predation, competition, and prey communities: a review of field experiments. Annu Rev Ecol Syst 16:269-311

Smith CL (1972) A spawning aggregation of Nassau grouper. Epinephelus striatus (Bloch). Trans Am Fish Soc 101: $257-261$

Smith CL, Tyler JC (1973) Direct observation of resource sharing in coral reef fish. Helgoländer Wiss Meeresunters 24 : $264-275$

Steger R (1987) Effects of refuges and recruitment on gon-

This article was submitted to the editor odactylid stomatopods, a guild of mobile prey. Ecology 68 $1520-1533$

Thrush S (1986) Community structure on the floor of a sealough: are large epibenthic predators important? J Exp Mar Biol Ecol 104:171-183

Underwood AJ, Denley EJ (1984) Paradigms, explanations, and generalizations in models for the structure of intertidal communities on rocky shores. In: Simberloff $D$, Strong DR, Abele L, Thistle AR (eds) Ecological communities: conceptual issues and the evidence. Princeton University Press, Princeton, NJ, p 151-180

Underwood AJ, Fairweather PG (1989) Supply-side ecology and benthic marine assemblages. TREE 4:16-20

Van Valen L (1974) Predation and species diversity. J Theor Biol 44:19-21

Victor BC (1983) Recruitment and population dynamics of a coral reef fish. Science 219:419-420

Victor BC (1986) Larval settlement and juvenile mortality in a recruitment-limited coral reef fish population. Ecol Monogr 56:145-160

Virnstein RW (1977) The importance of predation by crabs and fishes on benthic infauna in Chesapeake Bay. Ecology 58:1199-1217

Wahle RA, Steneck RS (1991) Recruitment habitats and nursery grounds of the American lobster Homarus americanus: a demographic bottleneck? Mar Ecol Prog Ser 69: 231-243

Warner RR, Hughes TP (1988) The population dynamics of coral reef fishes. Proc 6th Int Coral Reef Symp 1:149-155

Werner EE, Gilliam JF (1984) The ontogenetic niche and species interactions in size-structured populations. Annu Rev Ecol Syst 15:393-425

Williams DM (1980) Dynamics of a pomacentrid community on small patch reefs in One Tree Lagoon (Great Barrier Reef). Bull Mar Scl 30:159-170

Wilson WH (1991) Competition and predation in marine softsediment communities. Annu Rev Ecol Syst 21:221-241

Zar JH (1984) Biostatistical analysis, 2nd edn. Prentice-Hall, Englewood Cliffs, NJ

Zaret TM (1980) Predation and freshwater communities. Yale University Press, New Haven

Zimmer-Faust RK, Spanier E (1987) Gregariousness and sociality in spiny lobsters: implications for den habitation. J Exp Mar Biol Ecol 105:57-71

Manuscript first received: May 22, 1996

Revised version accepted: January 24, 1997 